\title{
Experimental investigation and thermo-mechanical modelling for tool life evaluation of photopolymer additively manufactured mould inserts in different injection moulding conditions
}

Davoudinejad, Ali; Bayat, Mohamad; Pedersen, David Bue; Zhang, Yang; Hattel, Jesper Henri; Tosello, Guido

Published in:

International Journal of Advanced Manufacturing Technology

Link to article, DOI:

10.1007/s00170-018-3163-7

Publication date:

2019

Document Version

Peer reviewed version

Link back to DTU Orbit

Citation (APA):

Davoudinejad, A., Bayat, M., Pedersen, D. B., Zhang, Y., Hattel, J. H., \& Tosello, G. (2019). Experimental investigation and thermo-mechanical modelling for tool life evaluation of photopolymer additively manufactured mould inserts in different injection moulding conditions. International Journal of Advanced Manufacturing Technology, 102(1-4), 403-420. https://doi.org/10.1007/s00170-018-3163-7

\section{General rights}

Copyright and moral rights for the publications made accessible in the public portal are retained by the authors and/or other copyright owners and it is a condition of accessing publications that users recognise and abide by the legal requirements associated with these rights.

- Users may download and print one copy of any publication from the public portal for the purpose of private study or research.

- You may not further distribute the material or use it for any profit-making activity or commercial gain

- You may freely distribute the URL identifying the publication in the public portal 


\title{
Experimental investigation and thermo-mechanical modelling for tool life evaluation of photopolymer additively manufactured mould inserts in different injection moulding conditions
}

\author{
A Davoudinejad, M Bayat, D B Pedersen, Y Zhang, J H Hattel, G Tosello \\ Department of Mechanical Engineering, Technical University of Denmark \\ DK-2800 Kgs. Lyngby, Denmark
}

\begin{abstract}
There is a growing interest for integrating additive manufacturing (AM) technology in different manufacturing processes such as injection moulding (IM) due to the possibility of achieving shorter manufacturing times and increased cost effectiveness. This paper evaluates IM inserts fabricated by the AM vat photopolymerization method. The inserts are directly manufactured with a photopolymer material, integrated on an injection moulding tool and subsequently used for IM. Therefore particular attention has to be paid in order to develop the soft tooling process chain and the IM experimental procedure as detailed in this study. Different combinations of IM parameters are investigated in this work in order to determine the influence of the various process settings on the inserts' performance (life time, crack propagation, consistency of the mould surface features). The mould inserts were analysed by three-dimensional optical metrology and evaluated with regards to the different surface features that were affected by the IM process. A three-dimensional thermo-mechanical with phase change model for the analysis of the effects of the IM process on the additive manufactured tools was accomplished in the FE software COMSOL Multiphysics. The potential causes for the insert failure are identified both by means of the IM experiments and the numerical model. The developed model could also predict the thermally induced deformations produced in the mould and identify where this phenomenon would eventually lead to defects in the shape of the parts. The influence of three different temperatures of the insert at $25^{\circ} \mathrm{C}, 50^{\circ} \mathrm{C}$ and $100^{\circ} \mathrm{C}$ on the failure of the insert was investigated. Also a detailed discussion about the solidification and temperature changes is given.
\end{abstract}

Keywords: Additive manufacturing; Vat photopolymerization; Injection moulding; Finite element modelling; Soft tooling

\section{Introduction}

Advances in high precision AM technologies, based on layer-by-layer deposition with different materials are opening new perspectives for manufacturing. AM methods are very well suited for single-part production of complex geometries. Several AM technologies are currently being applied for the fabrication of different components depending on the manufacturing scale, material, and dimension precision needed for the products. Many AM technologies find applications in the field of polymer part production and are rather well established for the rapid manufacturing of conventionally-sized components [1].

More recently, direct fabrication at miniature scale has appeared. For example, micro biological features produced by Digital Light Processing (DLP) could be realized using a 
photopolymer material: different designs were fabricated in order to evaluate the AM machine capability and a Tokay gecko test part that contains microscale pillars with widened tips was used as benchmark sample [2]. For the purpose, a novel DLP machine was specifically designed for precision printing, built and validated [3]. Another study investigated Twophoton polymerization process for fabrication of scaffolds for tissue engineering with minimum $200 \mathrm{~nm}$ feature of size [4]. Stereolithography (SLA) was applied for fabrication of different surfaces to evaluate self-cleaning and anti-sticking properties that find many potential industrial and biological applications. Micro pillars structures with dimension of 85 $\mu \mathrm{m}$ diameter were fabricated with this method [5].

Apart from rapid prototyping and the aforementioned methods for direct fabrication of components, AM has been used to integrate with other manufacturing processes such as injection moulding employed for mass production in different industries (medical devices, electronics, automotive, etc). For example, a study considered linking rapid prototyping with microinjection moulding for the mass production of different microtextures linked to tissue engineering tasks. The AM was used for insert fabrication and a thin-film deposition technique was applied for improving the surface conductivity, followed by an electroplating process to obtain micro mould inserts suitable for mass production. With the selected IM parameters and dedicated tooling and moulding equipment, more than 200 parts were produced, using both Poly methyl methacrylate (PMMA) and Polycarbonate (PC) thermoplastics suitable for medical applications [6]. Another soft tooling process chain was investigated in another study in micro IM [7]. The mould cavity was formed by two additively manufactured mould insert halves. Both inserts had four angled tines, with micro holes (diameter $200 \mu \mathrm{m}$, depth $200 \mu \mathrm{m}$ ) on the surface. The diameter and height of the pillars that were replicated on the moulded components were characterized by means of a 3D optical profilometer, and high surface replication fidelity was obtained. The injection moulding was continued until the insert cracked or otherwise stopped at 100 cycles and the influence of the injection moulding parameters on the replication was evaluated. Most of the production runs reached more than 80 cycles.

With material and tooling technology developments, longer tool lifetimes have become a reality, as reported by [8]. The AM stereolithography method was used to manufacture the injection moulding insert in a ceramic composite photopolymer. More than 10.000 parts were injection moulded successfully with one insert. One of the most significant reasons for the survival of the photopolymer insert was the low thermal conductivity $0.187 \mathrm{~W} /(\mathrm{m} . \mathrm{K})$ [9] of the employed photopolymer in comparison with other IM insert materials.

While previous works have mostly focused on experimental studies of soft tooling, some numerical modelling research has been carried out as well to investigate the behaviour of melt material and mould in detail. Cao et al. [10] applied the finite element method (FEM) to consider the viscoelastic behaviour of melt fluids during filling and after filling of the cavity in micro-injection moulding. Griffiths et al. [11] evaluated the influence of the process parameters on the micro flow while filling the channels. Polypropylene (PP) and Acrylonitrile Butadiene Styrene (ABS) were used as IM materials and the results validated against experimental results. In another study, the simulation and modelling of induction heating and filling of the cavity for ABS and a high viscosity polycarbonate (HVPC) polymer material were compared against experiments. The simulation results were in good agreement with experiments, both in terms of the thermal field and of the flow pattern [12]. The filling behaviour of polymer was investigated by La et al. [13] in a multi cavities mould. Flow rate, melt and mould temperatures were investigated the quality of the pillars arrays. The mould 
wall temperature was the most influential factor. Metwally et al. [14] studied the heat transfer with a 3D model with special focus on the thermal distribution in the contact area between mould and mould insert in the $\mu$-IM process. Choi and Kim [15] applied a multi-scale simulation in a way to first analyse the macro flow and then the micro cavity flow in the IM process. It was concluded that the proposed method could accurately integrate the effect of the conditions at the inlet location into the micro flow of the polymer melt. 3D filling simulations of micro and nanostructures were investigated in [16]. The heat transfer coefficient and the transition temperature were adjusted in the simulations and various IM conditions (mould temperature, injection velocity) were evaluated for polymethylmethacrylate (PMMA) and amorphous polyamide polymers.

Contributions in literatures have mostly focused on analysing the feasibility of the soft tooling process whereas failure evaluation analysis of the soft tooling is generally missing. A much more detailed evaluation would be required to assess the procedure and the conditions for soft tooling process. This study focuses on the evaluation of soft tooling inserts directly fabricated by the DLP additive manufacturing method. The significance of the setup and the necessary adjustments to avoid the failure of the insert are highlighted. Various IM parameters were applied in order to understand the effect of different settings on the inserts lifetime, crack propagation and consistency of the parts. The areas where the crack on the inserts initiated were identified for improvement of the insert design. The numerical model was employed to analyse the thermo-mechanical behaviour of the mould and the corresponding injection moulded parts in different processing conditions. The simulated failure of the inserts was compared against the experimental IM parts. Finally, conclusions are made about the sensitivity analysis of the soft tooling process parameters and the proposed simulation model.

\section{Experimental procedure}

\subsection{Mould insert fabrication and design}

The Digital Light Processing (DLP) technology was used as AM method for fabrication of the inserts. A high precision industrial 3D-printing system was used with a $50 \mu \mathrm{m}$ pixel detail in $X$ and $Y$ directions and an accuracy of $\pm 50 \mu \mathrm{m}$ in $X, Y$, and $Z$ directions. Due to the relatively large build volume (the envelope of the printing was $96 \times 54 \times 150 \mathrm{~mm}$ in the $X / Y / Z$ directions respectively), the inserts were printed in the same batch. The inserts' material was a methacrylic photopolymer. The insert design was selected based on previous research [8] in which the main part geometry consists of a plate $\left(20 \times 20 \times 2.5 \mathrm{~mm}^{3}\right)$ containing two cuboid structures with $800 \mu \mathrm{m}$ pillars attached as well as two heart-shaped elements. A draft angle of $2^{\circ}$ was added to the vertical walls to facilitate ejection of the injection moulded parts. Fig. 1 shows the AM insert and geometrical details. 


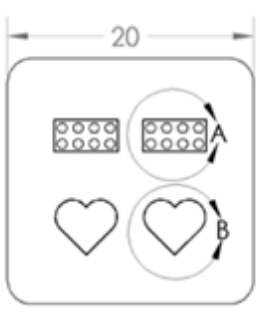

(a)

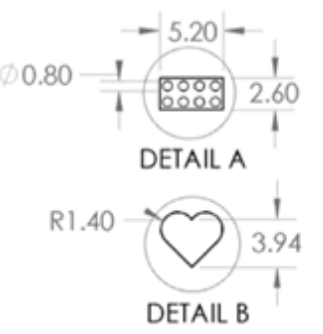

DETAIL B

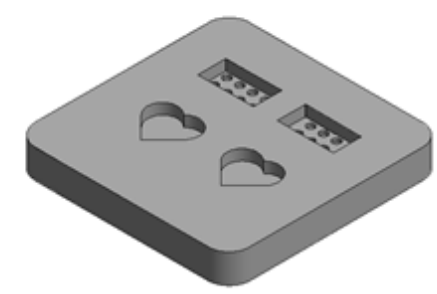

(b)

Fig. 1 (a) Sketch of the insert geometry; (b) AM insert.

\subsection{Injection moulding setup and adjustment for soft tooling}

The IM was carried out on an Arburg Allrounder 370A 600-70 Alldrive injection moulding machine with a clamping force of $600 \mathrm{KN}$ and a reciprocating screw having a diameter of 18 $\mathrm{mm}$. In order to investigate the IM parameters one cavity was used with AM insert for each moulding (Fig. 2). The IM material ABS Terluran GP-35 from INEOS Styrolution was selected. It had a recommended processing melt temperature range of $220-260^{\circ} \mathrm{C}$. The nature $A B S$ was mixed with $2 \%$ weight ratio black master batch. Due to the fabrication of the inserts with photopolymer material and its rather thin thickness $(2.7 \mathrm{~mm})$, it needed an initial plane correction of the insert to fit inside the IM tool steel mould block. An unlevelled insert may cause the polymer melt to run under the insert, filling the voids and instantly break the insert. Fig. 3(a) shows the experiment with the insert misalignment, which resulted in the failure. In order to feed the mould with a proper dosage of material, the short shots test was applied. $98 \%$ of the mould cavity was filled in five consecutive steps with increasing dosage as shown in Fig. 3 (c) and the remaining $2 \%$ of the cavity volume was filled during the packing phase. The packing pressure was adjusted to ensure that the cavity was properly filled to achieve full replication and to effectively compensate for shrinkage. The appropriate packing pressure level was found after an initial optimization experiment in which the pressure was raised to a maximum limit and checking the insert in order avoid damage. For example, when the packing pressure was raised up to 250 bar for $4 \mathrm{~s}$, it caused the insert damage shown in Fig. 3 (b). It is noticeable that the insert was deformed due to the excessive pressure in the cavity. The insert started to bend above the parts and the parts changed shape and became tilted. Eventually the packing pressure was set at 200 bar for a packing time of $4 \mathrm{~s}$. 


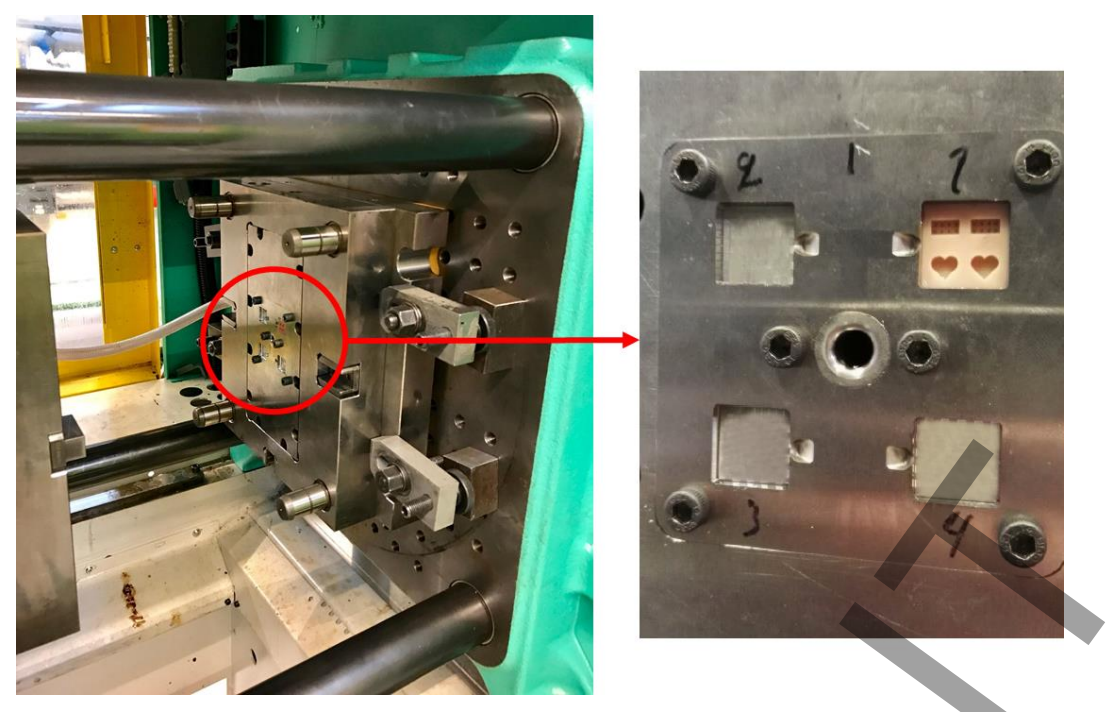

Fig. 2 Mould plate (injection side) (left) with an AM insert mounted in one cavity for injection moulding (right).

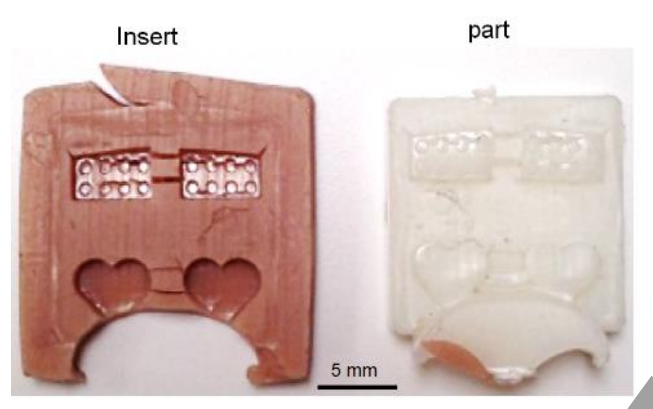

(a)

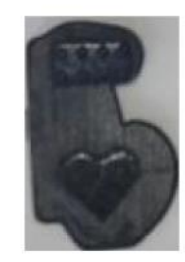

$3.70(\mathrm{~g})$

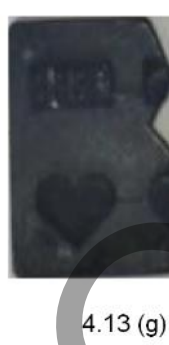

$4.13(\mathrm{~g})$

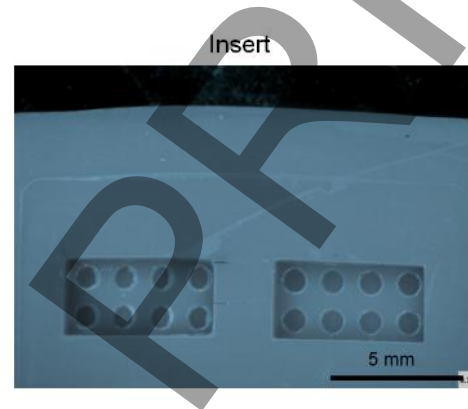

(b)

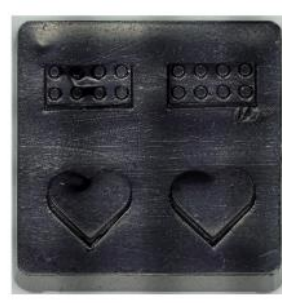

$4.8(\mathrm{~g})$
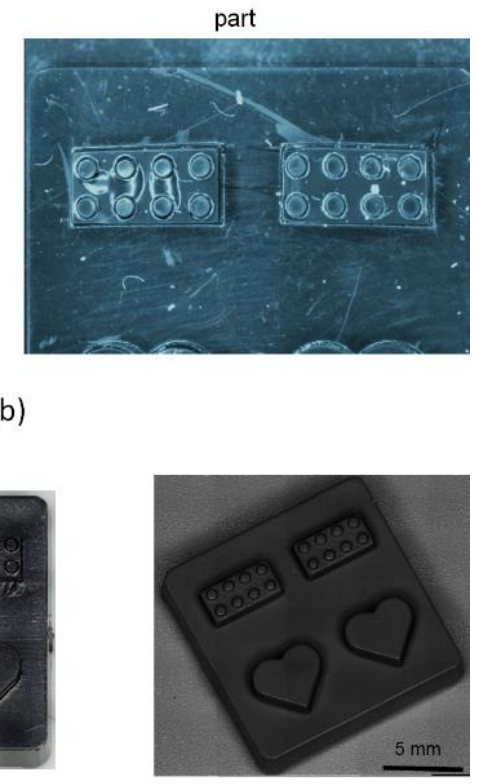

$4.98(\mathrm{~g})$ Final part

(c)

Fig. 3 (a) Mould insert damaged due to adjustment (b) insert failure by high packing pressure (c) short shots test in different dosage.

The Design of experiments (DOE) technique was applied to investigate the different parameters' contribution and distinguish between genuine effects of parameters and experimental errors. A $2^{4}$ experimental plan two-level fractional factorial DOE with 4 factors and a total number of eight experiments were carried out. The tested IM parameters are listed in the 'Soft tooling' column in Table 1. For reference, levels of the same IM parameters when moulding with different tool materials from the literature are presented in Table 1 . The factors were selected due to their importance on the soft tooling process chain. The values for the factors were selected based on the previously described optimization experiment as well as from literature. The temperature of the melt while injecting is an influential factor for 
the lifetime of the inserts. Moreover, the temperature of the mould is significant as the insert will be exposed to this temperature during the entire run time as opposed to the melt temperature which is only influential during the short injection time. The melt and mould temperature were chosen based on the data sheet for ABS Terluran GP-35 and from previous studies [17] [18]. The mould was heated by an externally controlled unit, with a temperature setting circuit for both mould sides. The injection speed, that is directly related to the maximum injection pressure reached inside the cavity, can be damaging if set at too high a level due to the fact that the insert was made of polymer instead of conventional tool steel. The injection speed level setting was inspired by [7] and the high level was raised up to 80 $\mathrm{mm} / \mathrm{s}$. Apart from the cooling in the closed mould to allow the part to solidify, an extra cooling time should be added. Cooling time depends on the insert geometry, the temperature environment, the temperature levels, the mould insulation and the conductivity of the insert material. The cooling time values were established after a screening experiment taking into account the relatively low conductivity of the photopolymer insert [9]. As mentioned, the remaining parameters for the packing phase were kept constant at 200 bar of packing pressure and $4 \mathrm{~s}$ of packing time. To carry out the DOE a randomization of the runs was applied.

Table 1 Injection moulding experimental factors and levels.

\begin{tabular}{c|cc|c|c|c}
\hline \multicolumn{2}{c}{ Soft tooling } & \multicolumn{2}{c|}{$\begin{array}{c}\text { Glass } \\
\text { mould [19] }\end{array}$} & \multicolumn{2}{c}{ Metal tooling [18][20] } \\
\hline Factors/ unit & Low & High & & Low & High \\
\hline packing time/s & $4 \mathrm{~s}$ & $4 \mathrm{~s}$ & $4 \mathrm{~s}$ & - & - \\
\hline $\begin{array}{c}\text { packing } \\
\text { pressure } / \text { bar }\end{array}$ & 200 & 200 & 400 & 280 & 390 \\
\hline $\begin{array}{c}\text { Melt } \\
\text { temperature } /{ }^{\circ} \mathrm{C}\end{array}$ & $220^{\circ} \mathrm{C}$ & $260^{\circ} \mathrm{C}$ & $237^{\circ} \mathrm{C}$ & 200 & 280 \\
\hline $\begin{array}{c}\text { Injection speed/ } \\
\mathrm{mm} / \mathrm{s}\end{array}$ & 40 & 80 & 10 & 200 & 800 \\
\hline $\begin{array}{c}\text { Mould } \\
\text { temperature } /{ }^{\circ} \mathrm{C}\end{array}$ & $25^{\circ} \mathrm{C}$ & $50^{\circ} \mathrm{C}$ & $22^{\circ} \mathrm{C}$ & 40 & 80 \\
\hline Cooling time $/ \mathrm{s}$ & 0 & 5 & 15 & 16 & 22 \\
\hline
\end{tabular}

\section{Measuring and analysis methods}

The measurement of the IM part features were performed using an Olympus Lext OLS 4100 laser scanning digital microscope equipped with a $5 \mathrm{X}$ magnification lens. In order to analyse the measurements data an image-processing software was employed for the purpose (SPIP ${ }^{\circledR}$ from Image Metrology). Fig. 4 shows the acquisition on the IM part surface of the knobs and the lower part of the heart from left to right, respectively. The measurements were carried out on the initial five IM parts in order to investigate the influence of IM parameters. The selected parts were measured before any crack appearance. 


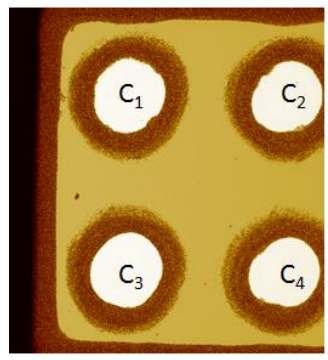

$1^{\text {st }}$ acquisition

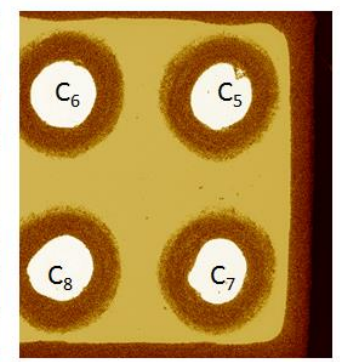

$2^{\text {end }}$ acquisition

(a)

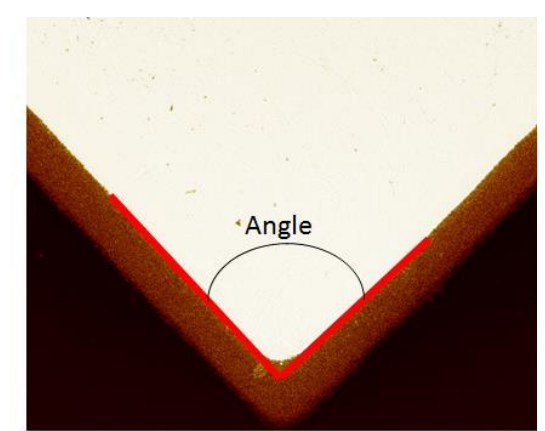

(b)

Fig. 4 Acquisition (a) of the brick eight circles measurements and (b) of the lower angle shape of the heart.

In order to assess the effects of moulding parameters on the injected moulded parts, certain areas of interest have been defined as shown in Fig. 5 . The selected measuring areas are marked in red. The circles indicate the diameter measurement areas of the knobs (measurements applied in both sides) (see details in Fig. 5(a)). Furthermore, the height of the features was measured as illustrated in Fig. 5(b). The selected areas were chosen as they were expected to be affected by the IM process and due to the fact that they are measurable with sufficient accuracy.

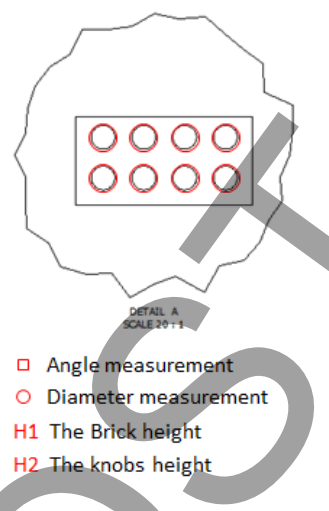

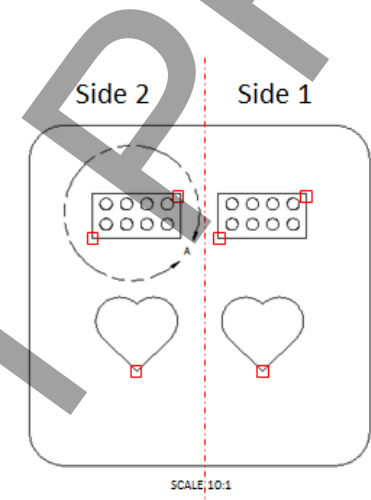

(a)

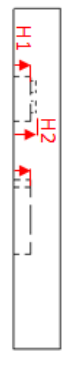

(b)

Fig. 5. Area of interest for the insert analysis (a) indication of surface roughness, diameter and angle measurements (b) indication of height measurements.

The moulded parts were collected respectively in order to follow the changes during the lifetime of the insert, as well as exactly identifying when the first crack appeared, as the insert itself could not be monitored during the IM. An image of each part was captured (Fig. 7) to track the changes of the cracks. The same crack was recorded for the subsequent batches to follow the crack propagation. In order to investigate exactly when and where the cracks started to appear, all inserts from each batch were examined. If the cracks were visually identified in a certain part, the previous part was inspected as well. If no cracks could be visually determined, further high resolution optical metrological analysis was employed for magnifying the area that led to a crack to ensure that no small cracks were present. The IM experiments in each condition were run until the breakage of the insert. The crack propagation speed was calculated based on the crack length and the number of shots when 
the crack appeared. The crack was measured on each part in different shots to determine when the critical failure of the inserts occurred.

\section{Numerical modelling}

In this work, a transient 3-dimensional thermo-mechanical finite element model including phase change is developed in order to investigate the effects of thermal loads inflicted by the molten material on the insert's mechanical behaviour as well as the parts' distortion. The COMSOL Multiphysics software is used for the thermo-mechanical simulation. The CAD model of the insert was separately generated and imported for the analysis. Also the process (filling) time for the simulations was adjusted based on the experiments. The simulations were carried out for different initial insert temperatures $\left(25^{\circ} \mathrm{C}, 50^{\circ} \mathrm{C}, 100^{\circ} \mathrm{C}\right)$. In this study it is assumed that the melt was initially at rest at $260^{\circ} \mathrm{C}$ uniformly. The melting point for the IM part is $220^{\circ} \mathrm{C}$, so a $40^{\circ} \mathrm{C}$ superheating is considered for the initial melt temperature.

\subsection{Thermal model}

Fourier's heat conduction equation which expresses energy conservation in both insert and melt, governs the thermal behaviour of the parts [21]:

$$
\rho C_{p} \frac{\partial T}{\partial t}=\frac{\partial}{\partial x}\left(k_{x} \frac{\partial T}{\partial x}\right)+\frac{\partial}{\partial y}\left(k_{y} \frac{\partial T}{\partial y}\right)+\frac{\partial}{\partial z}\left(k_{z} \frac{\partial T}{\partial z}\right)+\rho \cdot L H \cdot \frac{\partial f_{s}}{\partial t}
$$

Where $\left(k_{x}, k_{y}, k_{z}\right)$ are thermal conductivities $\frac{W}{m . K}$ in $\mathrm{x}, \mathrm{y}$ and $\mathrm{z}$ directions. $\rho$ and $C_{p}$ are the density $\frac{\mathrm{kg}}{\mathrm{m}^{3}}$ and the specific heat capacity $\frac{\mathrm{J}}{\mathrm{kg} \cdot \mathrm{K}^{\prime}}$, respectively.

The last term of the right hand side of equation (1) is a volumetric heat generation source term which, is only active for the melt and just during the solidification process. Thus, when this equation is used for the insert, this heat source will be absent, since no phase change occurs for the insert. $\mathrm{LH}$ is the latent heat of fusion and $f_{S}$ is the solid volume fraction, where the latter is assumed to be a linear function of temperature:

$$
f_{s}=\left\{\begin{array}{cl}
0 & T>T_{\text {liq }} \\
\frac{T-T_{\text {liq }}}{T_{\text {sol }}-T_{\text {liq }}} & T_{\text {sol }} \leq T \leq T_{\text {liq }} \\
1 & T_{\text {sol }}<T
\end{array}\right.
$$

Where, $T_{\text {liq }}$ and $T_{\text {sol }}$ are the liquidus and solidus temperatures of the molten material. To solve equation (1), the source term can be easily rewritten into the following by the chain rule:

$$
\rho . L H \cdot \frac{\partial f_{s}}{\partial t}=\rho \cdot L H \cdot \frac{\partial f_{s}}{\partial T} \frac{\partial T}{\partial t}
$$

Rearranging by moving this term to the left hand side of equation (1), it becomes; 
$\rho \cdot\left(C_{p}(T)-L H \cdot \frac{\partial f_{s}}{\partial T}\right)$

The apparent heat capacity during phase change can hence be calculated as [22] [23]:

$$
C_{p}^{*}=C_{p}(T)-L H \cdot \frac{\partial f_{s}}{\partial T}
$$

According to equation (5), during the solidification where the solid volume fraction changes with temperature (and this derivative is negative), the apparent heat capacity rises to $C_{p}(T)-L H \cdot \frac{\partial f_{s}}{\partial T}$ whereas outside the solidification interval, it again becomes $C_{p}(T)$.

In this paper, volume-averaged relations for calculating the thermal properties are used. For simplicity, the apparent specific heat capacity and thermal conductivity, are assumed to be linear functions of the liquid fraction of the melt:

$$
\begin{aligned}
& C_{p}=f_{s} \cdot C_{p, s}+\left(1-f_{s}\right) \cdot C_{p, l} \\
& k=\frac{f_{s}}{k_{s}}+\frac{1-f_{s}}{k_{l}}
\end{aligned}
$$

The thermal and mechanical properties of the insert and the melt are presented in Table 2 .

Table 2 Thermal and mechanical properties parameters applied for the simulation [24] [25].

\begin{tabular}{ll}
\hline Property & Definition \\
\hline$C_{p_{, S}}=1470 \frac{\mathrm{J}}{\mathrm{kg} \cdot \mathrm{K}}$ & Specific heat capacity of solid \\
$C_{p_{, l}}=1700 \frac{\mathrm{J}}{\mathrm{kg} \cdot \mathrm{K}}$ & Specific heat capacity of liquid \\
$k_{S}=0.3 \frac{\mathrm{W}}{\mathrm{m} \cdot \mathrm{K}}$ & Thermal conductivity of solid \\
$k_{l}=0.2 \frac{\mathrm{W}}{\mathrm{m} \cdot \mathrm{K}}$ & Thermal conductivity of liquid \\
$\rho_{S}=1040 \frac{\mathrm{kg}}{\mathrm{m}^{3}}$ & Solid density \\
$\rho_{l}=1040 \frac{\mathrm{kg}}{\mathrm{m}^{3}}$ & Liquid density \\
$L H=190 \frac{\mathrm{kJ}}{\mathrm{kg}}$ & Specific heat conductivity of insert \\
$C_{p_{, I}}=990 \frac{\mathrm{J}}{\mathrm{kg} \cdot \mathrm{K}}$ & Thermal conductivity of insert \\
$k_{I}=1.0 \frac{\mathrm{W}}{\mathrm{m} \cdot \mathrm{K}}$ &
\end{tabular}




$$
\begin{array}{ll}
\rho_{I}=1100 \frac{\mathrm{kg}}{\mathrm{m}^{3}} & \text { Density of insert } \\
Y_{\left(T=20^{\circ} \mathrm{C}\right)}=90 \mathrm{MPa} & \text { Tensile strength of insert at } \mathrm{T}=20^{\circ} \mathrm{C} \\
E_{\left(T=20^{\circ} \mathrm{C}\right)}=1900 \mathrm{MPa} & \text { Elastic modulus of insert at } \mathrm{T}=20^{\circ} \mathrm{C} \\
C_{p_{s t}}=450 \frac{\mathrm{J}}{\mathrm{kg} \cdot \mathrm{K}} & \text { Specific heat capacity of steel } \\
k_{s t}=40 \frac{\mathrm{W}}{\mathrm{m} \cdot \mathrm{K}} & \text { Thermal conductivity of steel } \\
\rho_{s t}=7800 \frac{\mathrm{kg}}{\mathrm{m}^{3}} & \text { Density of steel }
\end{array}
$$

\subsubsection{Boundary and initial conditions}

In this work it is assumed that both insert and melt are initially at rest at their corresponding uniform temperatures:

$$
\begin{aligned}
& \left.T\right|_{(x, y, z \in D, t=0)} ^{\text {Insert }}=[25,50,100]^{\circ} \mathrm{C} \\
& \left.T\right|_{(x, y, z \in D, t=0)} ^{m e l t}=[260]^{\circ} \mathrm{C}
\end{aligned}
$$

According to (7), three different initial uniform temperatures are considered for the insert, while for the melt a $40^{\circ} \mathrm{C}$ superheat is assumed.

The melt-insert-steel assembly and its corresponding equivalent lumped thermal model are both shown in Fig. 6. According to Fig. 6, the top and bottom sides of the melt and insert respectively, are in contact, first with a thick steel piece and subsequently to the ambient, where the heat is transferred to the air and surroundings via either natural convection or radiation. . In this regard, the thick steel layers will play an important role during the heat transfer process. Moreover, considering the whole steel layer as part of the computational domain, especially due to its relatively big size, will increase the computational costs to a large degree. Consequently, a thick thermal layer is implemented to account for the transient thermal behaviour of the neighbouring steel layers. The thick thermal layer consists of an equivalent thermal capacitor and a thermal resistance. The thick thermal layer is shown by the blue dashed line in Fig. 6 . The thermal capacitor hence simulates the steel layer's transient behaviour in a lumped simplification.

Additionally, to thermally couple both steel layer and the melt/insert assembly, a contact boundary condition is imposed on the contact surfaces $\varphi$ and $\psi$ (contacts shown in red dashed lines in Fig. 6. at top and bottom of the melt/insert assembly). The mathematical representation of these two contact boundary conditions can be expressed as:

$$
\left.k_{s t} \frac{\partial T}{\partial n}\right|_{\varphi, \psi}=\left.k_{M / I} \frac{\partial T}{\partial n}\right|_{\varphi, \psi}
$$


$\left.T_{s t}\right|_{\varphi, \psi}=\left.T_{M / I}\right|_{\varphi, \psi}$

The subscripts st and $\mathrm{m} / \mathrm{l}$ stand for steel and melt/insert assembly respectively. Also the subsequent thermal interaction between the steel layers and the ambient, which occurs on the outer surfaces can be written as:

$$
\begin{aligned}
& -\left.k_{s t} \frac{\partial T}{\partial n_{s t}}\right|_{\omega, \chi}=h_{c o n v}\left(T-T_{a m b}\right)+h_{r}\left(T-T_{a m b}\right) \\
& h_{r}=\varepsilon \sigma\left(T+T_{a m b}\right)\left(T^{2}+T_{a m b}^{2}\right)
\end{aligned}
$$

Where $h_{\text {conv }}$ on the right hand side of equation (11) is the convective heat transfer coefficient $\frac{W}{m^{2} \cdot K}$. $\varepsilon$ and $\sigma$ in (12) are surface emissivity and Stefan-Boltzmann constant $\frac{W}{m^{2} \cdot K^{4}}$ for radiation, respectively. $\omega$ and $\chi$ stand for the steel/ambient contact surfaces on top and bottom of the assembly as shown in Fig. 6.

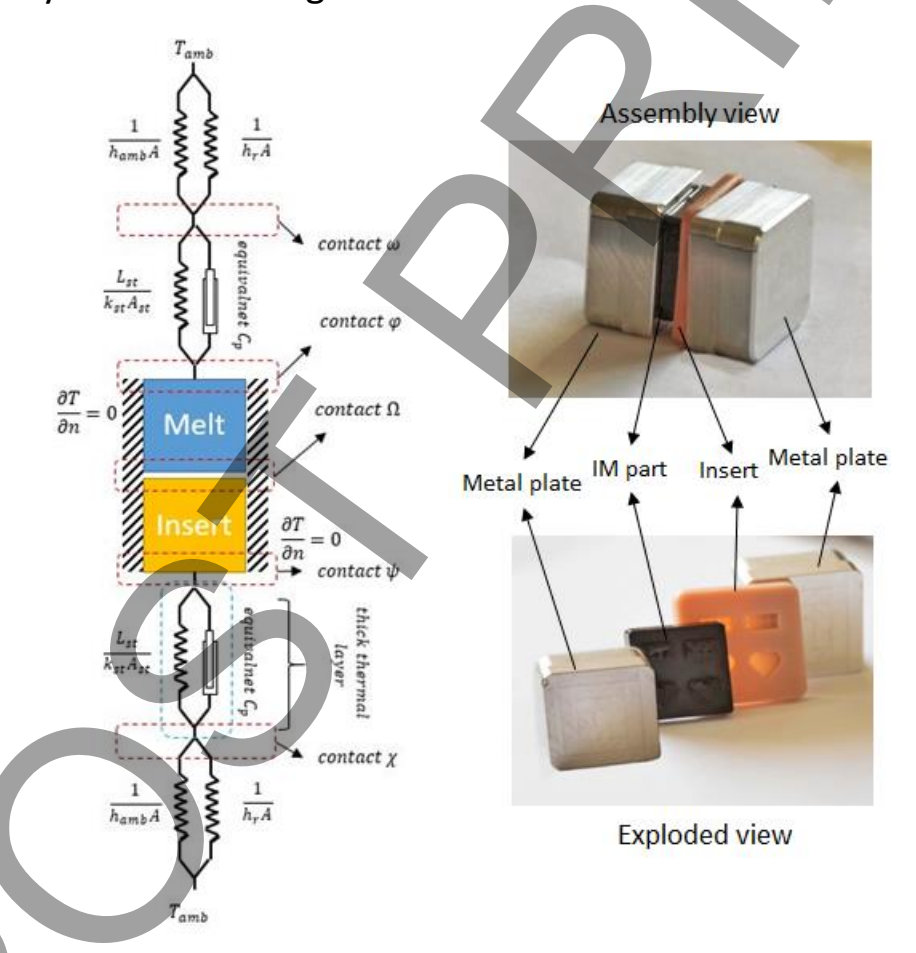

Fig 6. (left) Thermal model and (right) the actual shape of the melt (part)/insert/steel assembly.

To take into the mutual thermal interaction between melt and insert account, another contact boundary condition is imposed on the melt/insert interface (designated $\Omega$ in Fig. 6), which can be expressed as:

$$
\begin{aligned}
& \left.k_{M} \frac{\partial T}{\partial n}\right|_{M, \Omega}=\left.k_{I} \frac{\partial T}{\partial n}\right|_{M, \Omega} \\
& \left.T_{M}\right|_{M, \Omega}=\left.T_{I}\right|_{M, \Omega}
\end{aligned}
$$


The subscripts $M$ and I stand for melt and insert domains. According to (13) and (14), the temperature and heat fluxes should remain the same on this interface for the two parts, according to (13) and (14).

The melt and insert were meshed with 4-node tetrahedral elements with maximum and minimum sizes of $1.1 \mathrm{~mm}$ and $0.08 \mathrm{~mm}$ respectively. A total of 67279 elements is used for the thermal model as well as the mechanical model. To attain a better resolution over the fine features in both melt and insert, a higher mesh density with smaller element sizes were considered as shown in Fig. 7.

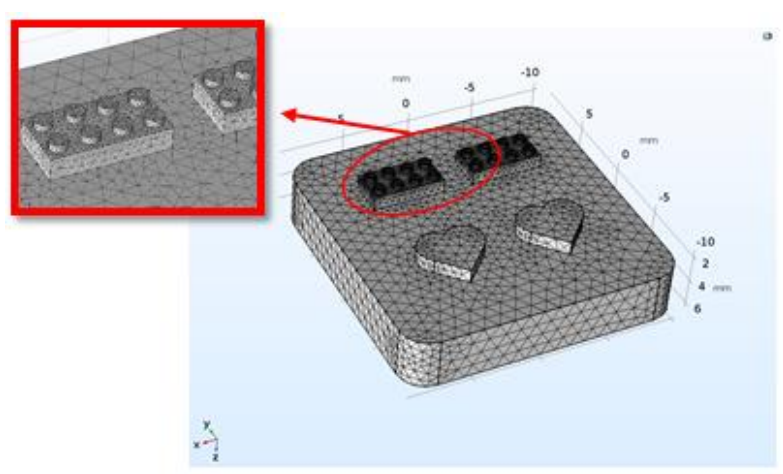

(a)

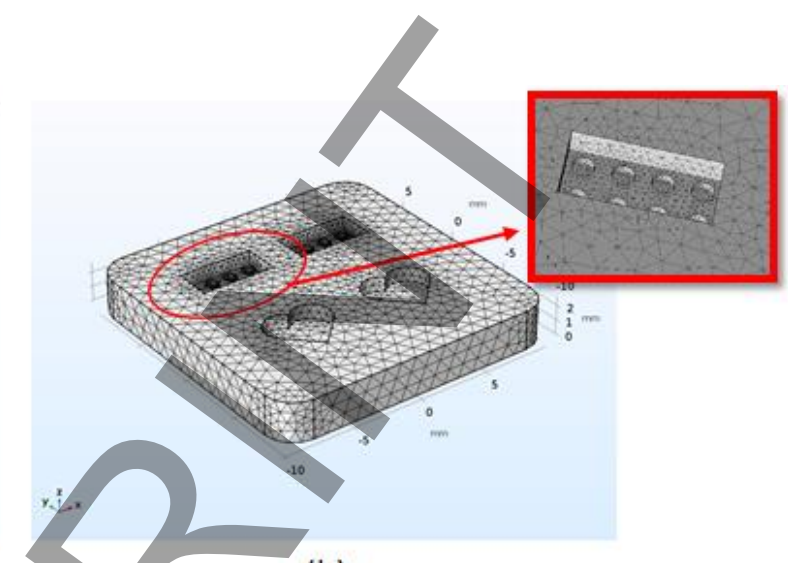

(b)

Fig. 7. 3D model with mesh for (a) melt material and (b) mould.

\subsection{Mechanical model}

A mechanical model has also been developed to study the effect of thermally-induced stresses on the insert. Based on the generalized Hooke's law, the relation between the stress and elastic strains in three dimensions, in tensor notations are given as [26] [27] [28]:

$$
\begin{aligned}
& \dot{\epsilon}^{E}{ }_{i j}=L_{i j k l} \dot{\sigma}_{k l} \\
& L_{i j k l}=\frac{E}{1+v}\left[\frac{1}{2}\left(\delta_{i k} \delta_{j l}+\delta_{i l} \delta_{j k}\right)+\frac{v}{1-2 v} \delta_{i j} \delta_{k l}\right]
\end{aligned}
$$

In (14) $\dot{\sigma}$ and $\dot{\epsilon}^{E}$ stand for the incremental stresses and strains. In (15), $E$ is the Young's modulus $(\mathrm{Pa})$ and $v$ is the Poisson's ratio. The thermal strains that occur due to thermal expansion, can be expressed as:

$$
\epsilon^{t h}=\int_{T_{r e f}}^{T(x, y, z, t)} \alpha d T
$$

$\alpha$ is the coefficient of thermal expansion (1/K) which plays a crucial role in coupling the thermal model to the mechanical model. $T_{r e f}$ is the reference temperature, which for this work is assumed to be the same as the ambient temperature, hence at room temperature 
there won't be any thermal strains for the insert. The stress was calculated only for the insert, not for the melt.

The main partial differential equations which govern the mechanical behaviour of the parts, are the equilibrium equations which expresses the balance of internal and external forces

$$
\sigma_{i j, j}+F_{i}=0
$$

$u_{i}$ and $F_{i}$ in (17) are displacement $[m]$ and volume force $\left[\frac{N}{m^{3}}\right]$, respectively. $\sigma_{i j, j}$ is the wellknown divergence of the stress tensor. In this study the Von Mises equivalent stress has been chosen as a means of expressing the equivalent stress state in a point when presenting the results from this otherwise thermo-elastic analysis, i.e.:

$$
\sigma_{\text {Mises }}^{2}=\frac{3}{2} s_{i j} s_{i j}=\frac{1}{2}\left[\left(\sigma_{I}-\sigma_{I I}\right)^{2}+\left(\sigma_{I I}-\sigma_{I I I}\right)^{2}+\left(\sigma_{I I I}-\sigma_{I}\right)^{2}\right]
$$

Where $\sigma_{I}, \sigma_{I I}, \sigma_{I I I}$ are the principal stresses in $\mathrm{x}, \mathrm{y}$ and $\mathrm{z}$ directions and $s_{i j}$ is the deviatoric stress tensor:

$$
s_{i j}=\sigma_{i j}-\frac{1}{3} \delta_{i j} \sigma_{k k}
$$

\section{Results and analysis}

\subsection{Influence of IM parameters in tool life}

After preparation of the setup for soft tooling, all the IM DOE runs were carried out as described in the previous sections. The tool life of the inserts was evaluated by the number of shots. The IM was continued to determine the number of shots that the insert can withstand in the selected setting parameters. The cracks occurred in different regions of the inserts as shown in Fig. 8(a). The blue arrow on the right side of the insert shows the gate location as well as the injection direction. Five areas were considered to be prone to cracks. The table below Fig. 8(a) represents the number of inserts and locations where the cracks appeared. The inserts had a tendency to crack on the opposite walls from the gate and in a direction parallel to the injection direction. It was noticed on the top corner of the bricks that cracking happened in most of the inserts and then on the wall between two features on each side of the insert. Fig. 8 (b) to (g) show the IM parts fabricated in different shots and areas of the inserts. The propagation of cracks is visible in different shots and they finally result in the failure of the insert. The failure was considered when the experiment was stopped due to the defect on the insert as shown in Fig. 8(d) at 143 shots and Fig. 8(f) shows the front and back of the insert with the IM part inside which was instantly cracked after 110 shots. It was also noticed that the crack propagation speed greatly increased, when the crack was located in a thin section such as between the features (Fig. 8(e) and (d)).

Apart from the location of cracks, the life time of the inserts were evaluated with crack propagation speed. The number of shots when the cracks started were recorded and the propagation speed was analyzed. The calculated propagation speeds for each crack location on each sample as a function of the IM parameters can be found in Table 3. The crack direction 
was noticed on the melt flow direction inside the mould and started to grow the same way (Fig. 8(d) and (g)). The response for the DOE analysis was selected based on the tool life of the inserts. The IM parts after crack on the insert was considered as not functional parts. Table 3 presents the IM test conditions with the number of shots up to the failure of the inserts. The significance of parameters is shown in Fig. 9 with the main effects plot and Pareto chart for the DOE analysis with crack speed as the response. It was revealed that the mould temperature was the most influential factor out of the four selected IM parameters with regard to the crack speed.

Table 3 DOE results for additively manufactured polymer inserts after injection moulding. $\left({ }^{*}\right)$ the interval refers to the standard deviation/ the uncertainty of the measurement.

\begin{tabular}{ccccccc}
\hline Test & $\begin{array}{c}\text { Melt } \\
\text { temp. } \\
{\left[{ }^{\circ} \mathrm{C}\right]}\end{array}$ & $\begin{array}{c}\text { Inj. } \\
\text { speed } \\
{[\mathrm{mm} / \mathrm{s}]}\end{array}$ & $\begin{array}{c}\text { Mould } \\
\text { temp. } \\
{\left[{ }^{\circ} \mathrm{C}\right]}\end{array}$ & $\begin{array}{c}\text { Cooling } \\
\text { time }\end{array}$ & $\begin{array}{c}\text { Crack speed } \\
{[\mu \mathrm{m} / \text { shot }]}\end{array}$ & $\begin{array}{c}\text { Critical } \\
\text { failure }\end{array}$ \\
\hline $\mathrm{A}$ & 220 & 80 & 25 & 5 & $28.0 \pm 2(* 1.37)$ & 110 \\
$\mathrm{~B}$ & 260 & 40 & 50 & 0 & $235.0 \pm 4(* 3.13)$ & 25 \\
$\mathrm{C}$ & 220 & 80 & 50 & 0 & $221.0 \pm 3(* 2.61)$ & 30 \\
$\mathrm{D}$ & 260 & 40 & 25 & 5 & $36.0 \pm 2(* 1.52)$ & 49 \\
$\mathrm{E}$ & 220 & 40 & 25 & 0 & $26.0 \pm 1(* 0.68)$ & 143 \\
$\mathrm{~F}$ & 220 & 40 & 50 & 5 & $123.0 \pm 2(* 1.25)$ & 63 \\
$\mathrm{G}$ & 260 & 80 & 50 & 5 & $151.0 \pm 3(* 2.23)$ & 26 \\
$\mathrm{H}$ & 260 & 80 & 25 & 0 & $43.0 \pm 2(* 1.42)$ & 35 \\
\hline
\end{tabular}




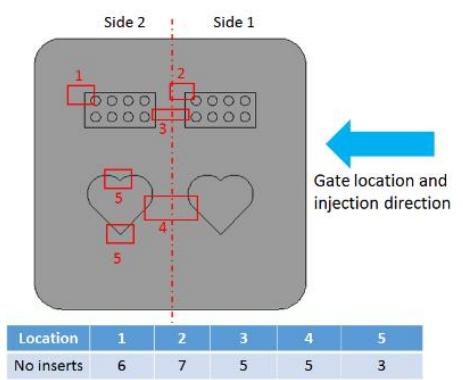

(a)

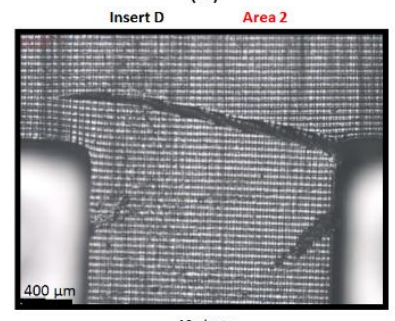

(b)

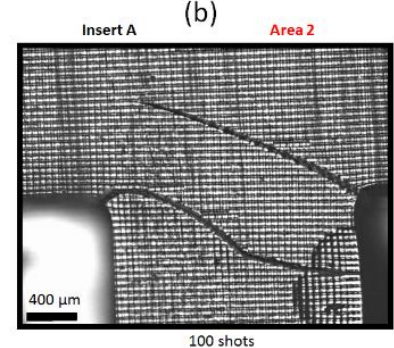

(c)

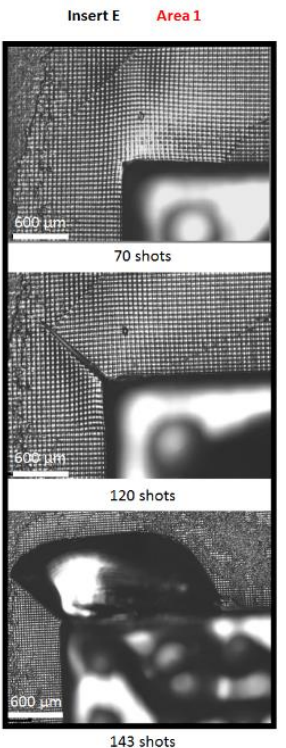

(d)

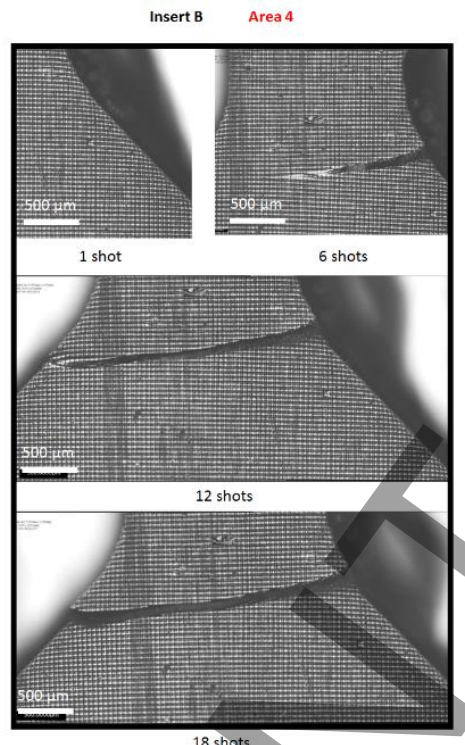

(e)

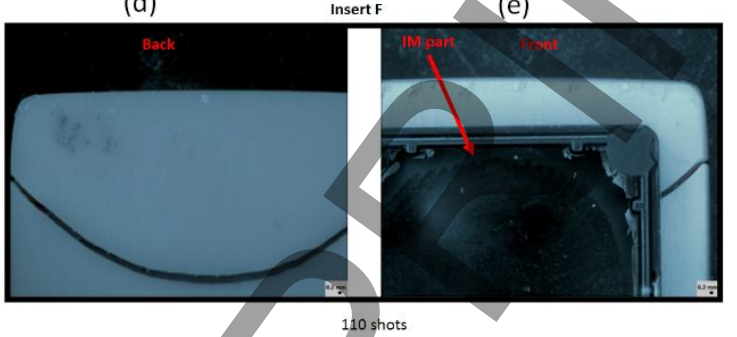

(f)

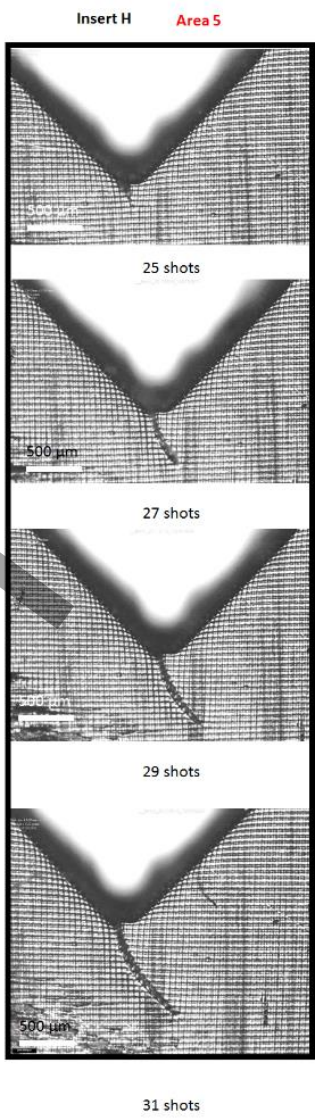

(g)

Fig. 8 (a) Crack locations on the insert; (b) and (c) moulded parts cracks; (d)-(g) crack propagation on the IM parts in different shots.

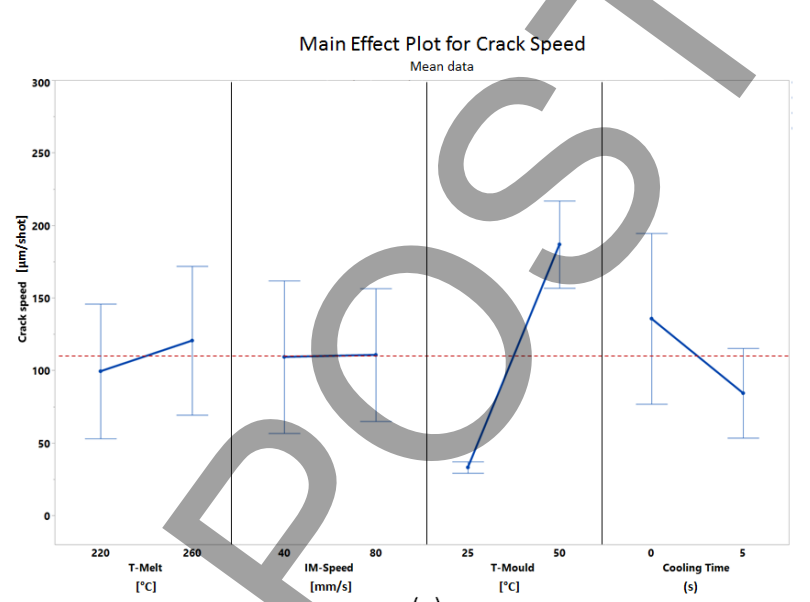

(a)

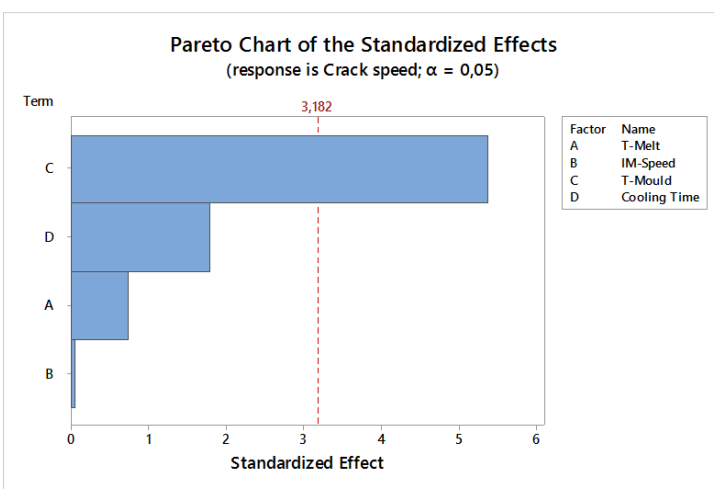

(b)

Fig. 9. (a) Main effect plot (the error bar presents the standard deviation) (b) Pareto chart of the standardized effects in response to speed of cracks.

In a high number of IM shots with crack propagation, failure in the insert occurred and the effect was observed in the moulded parts' features as shown in Fig. 10. The deformation was detected mainly on the wall for both types of features. The failure of the features started from the side of the insert which was farther from the gate location. 

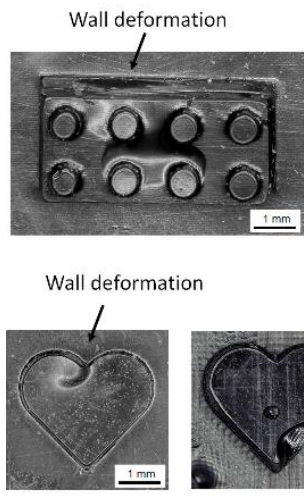
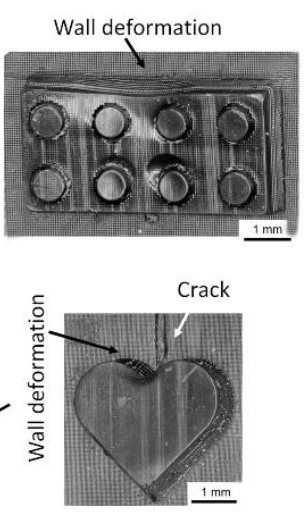

Crack
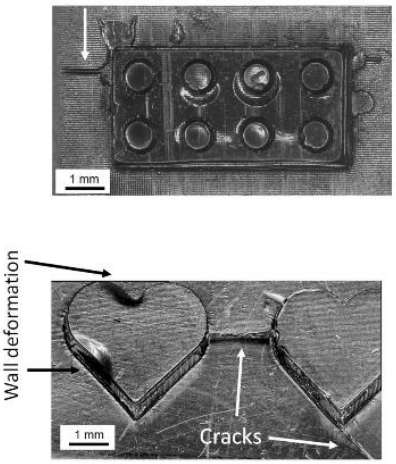

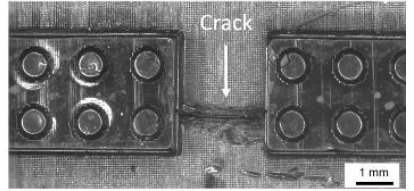

Wall deformation

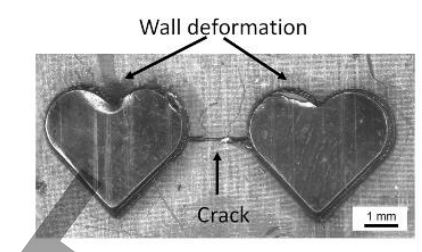

Fig. 10 IM parts failure with crack propagation.

\subsection{Replication of IM parts features}

The micro features were evaluated by the average diameter of the knobs. The DOE main effects and interaction plots with the diameter as response are shown in Fig. 11(a) and Fig. 11(b) respectively. The DOE result shows the significance of mould temperature $\left(25^{\circ} \mathrm{C}\right)$ and cooling time ( $5 \mathrm{~s})$ for the repeatability of the features' fabrication. With a lower mould temperature and longer cooling time a higher replication of the features geometries were obtained due to the improved filling conditions of the knobs on the insert. The interaction plot in the second order terms (full interaction plot matrix) shows that the combination of (TMelt \& IM-Speed), (T-Melt \& Cooling Time) and (T-Mould \& T-Melt) are significant factors for the replication of the knobs diameter. Regarding the diameter of the knobs, Fig. 11(c) presents the symmetrical features size in both sides of the mould. It was revealed that on the first side of the mould which was close to the gate, a slightly larger diameter of features were obtained in all the batches. With respect to the height of the bricks and knobs Fig. 11(d) shows the average height measurements for each test. The replication of the height illustrated that the knobs were more affected in different test conditions due to the smaller size of the feature. However, the brick height demonstrated less variation in different IM conditions. The replicated features were more influential in the smaller size features.

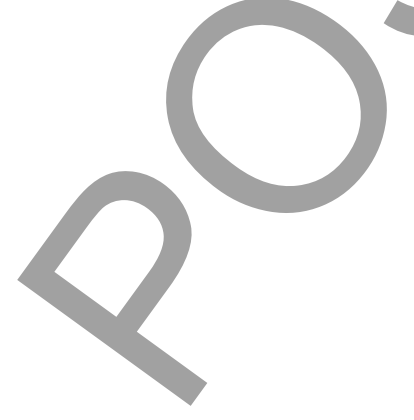




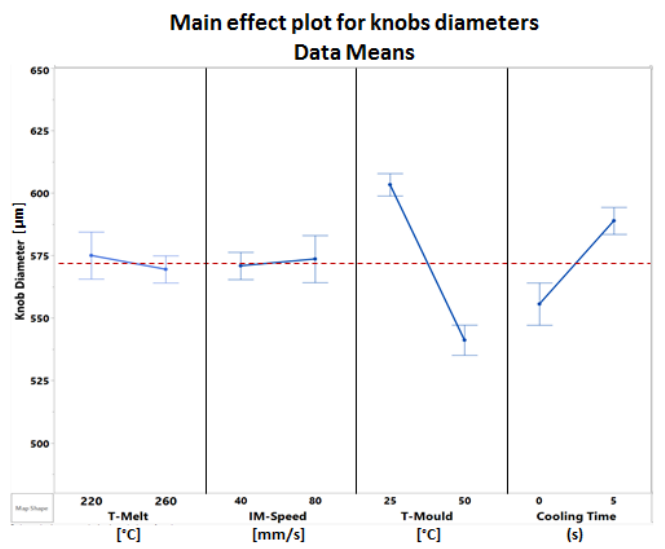

(a)

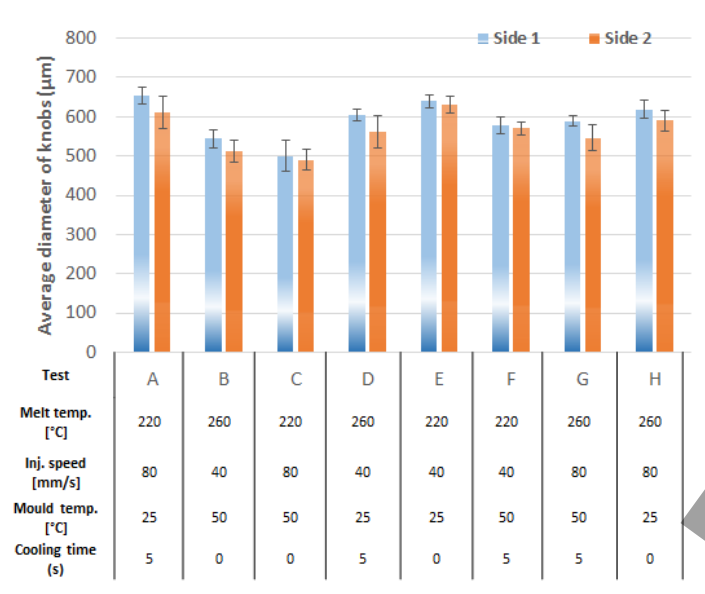

(c)

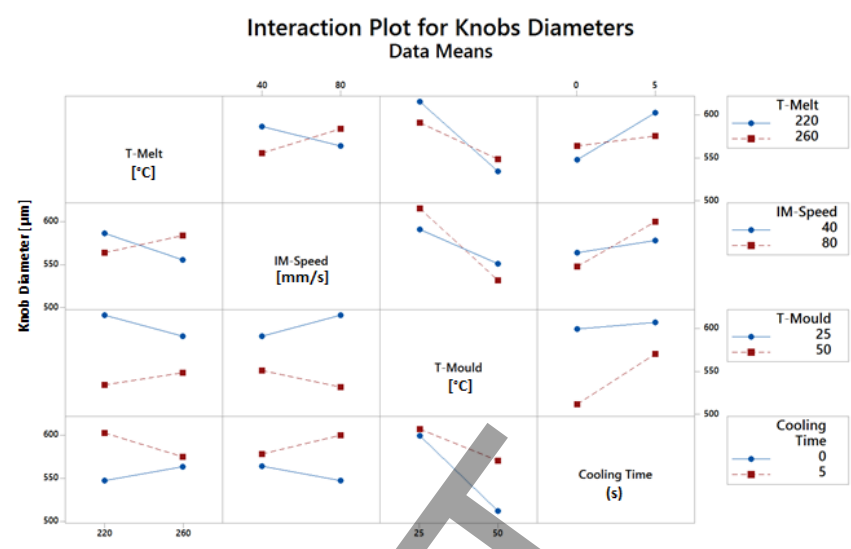

(b)

$=$ Average height $\mathrm{H} 2(\mathrm{~mm})$ Nominal height $\mathrm{H} 2(\mathrm{~mm})$

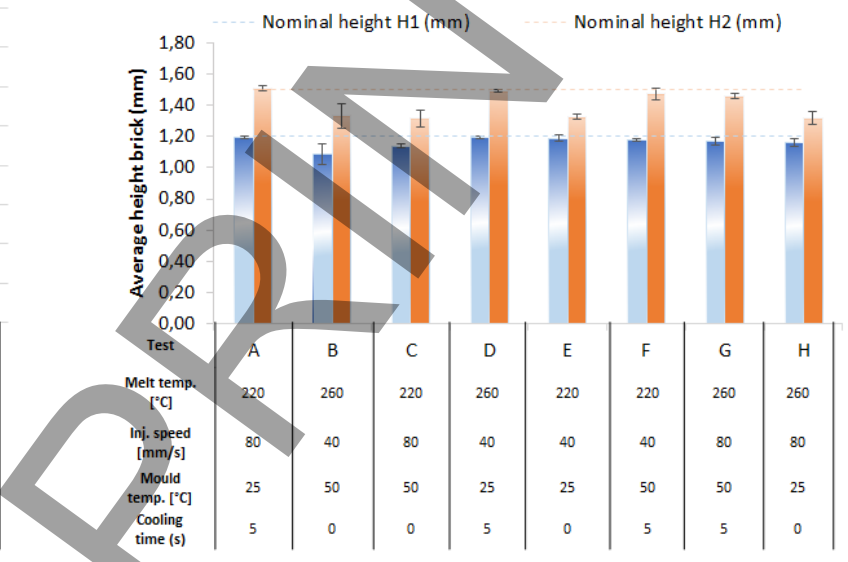

(d)

Fig. 11. (a) Main effect plot (the error bar presents the standard deviation) (b) Interaction plot(c) knobs diameter in each side of the parts (d) the height of the bricks and knobs.

\subsection{Numerical results}

\subsubsection{Temperature field}

As mentioned earlier, the temperature distribution in the insert and melt were determined for the three predefined initial insert temperatures of $25{ }^{\circ} \mathrm{C}, 50{ }^{\circ} \mathrm{C}$ and $100{ }^{\circ} \mathrm{C}$. The temperature contour in the insert and melt at different timescales during the process is presented in Fig. 12. After the first 3 seconds in which insert and molten material have just come into contact with each other, hot spots are formed in some locations on the insert surface, which are designated by black dashed lines in Fig. 12 (see results at $t=1 \mathrm{~s}$ and $\mathrm{t}=3 \mathrm{~s}$ ). The four holes in the insert contain a specified amount of hot liquid material and during the solidification of this liquid material, a relatively high amount of energy, specially due to release of latent heat of fusion of the melt, will be transferred to the neighbouring insert walls. This is the main underlying reason for the formation of hot spots in the first $3 \mathrm{~s}$ of the process, as highlighted with dashed curves in Fig. 12. As will be discussed in the following sections, regarding the analysis of thermal stresses, the formation of these hotspots will become one of the most important factors which prompt the fracture of the insert. 
The next step in the heat transfer process is the accumulation of the heat from the top surface of the insert (melt-insert interface) to its bottom surface, where the insert is in contact with the neighbouring steel layer (insert-steel interface), see Fig. 12. This step occurs right after the time when all the liquid material contained in the four part cavities is solidified. Then, due to solidification, the latent heat of fusion of molten material will release in two up and down directions into the insert and steel layers respectively, as demonstrated in Fig. 12 at $t=5$ and $\mathrm{t}=10 \mathrm{~s}$. At $\mathrm{t}=20 \mathrm{~s}$, both insert and molten material assume a nearly identical average temperature and finally both of them will approach the ambient temperature. After that, since there is no significant temperature differences in the two parts, the rate of heat transfer decreases. 

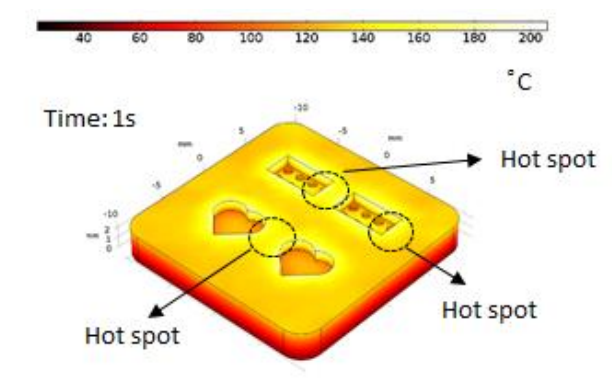

Time: $3 \mathrm{~s}$

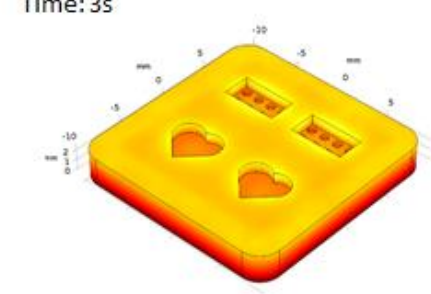

Time: $5 \mathrm{~s}$

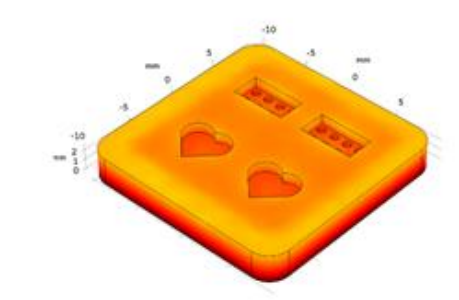

Time: 10 s

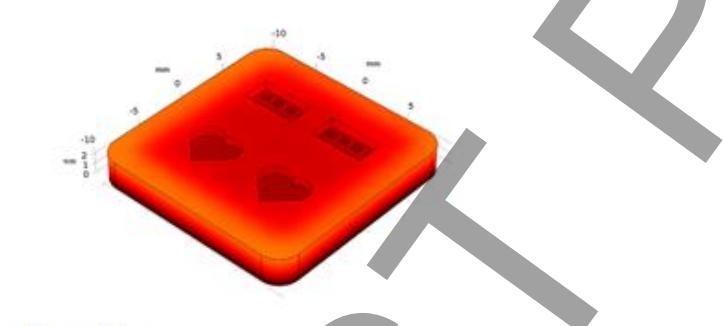

Time: $20 \mathrm{~s}$

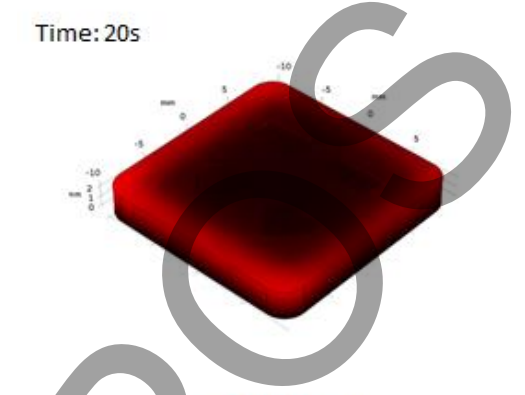

AM Insert
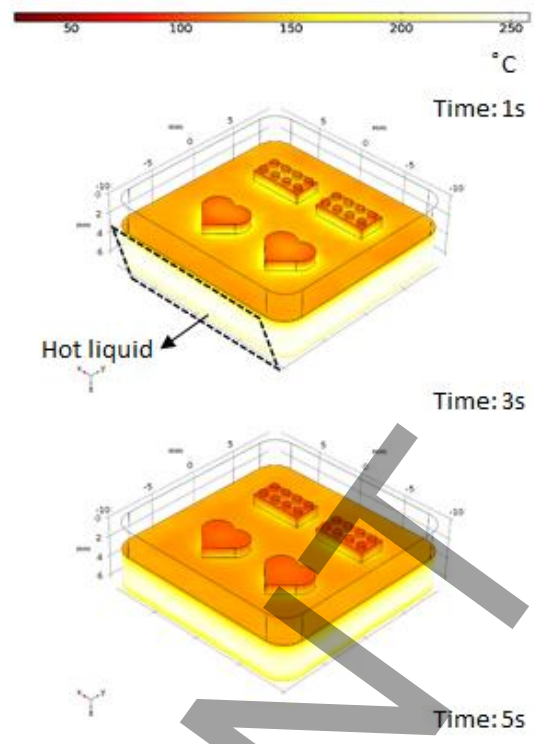

Time: $10 \mathrm{~s}$

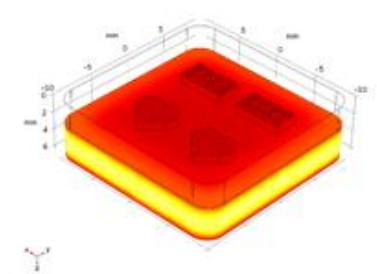

Time: $20 \mathrm{~s}$

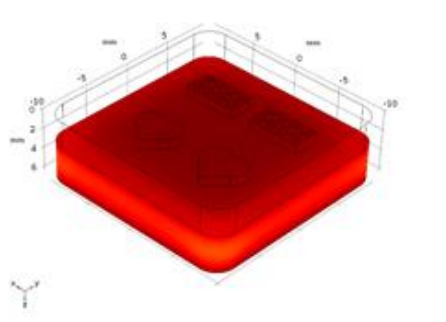

IM melt

Fig 12. Temperature distribution in insert at various times for the additively manufactured insert (left) and the injection moulded molten material (right).

The thermal interaction between both molten material and insert can be well understood from Fig 13. In this figure, the upper part is the melt while the bottom one is the insert. Moreover, according to Fig 13, the melt (the upper part in Fig 13) starts to cool down in two different up and down directions ( $a t \mathrm{t}=3 \mathrm{~s}$ and $\mathrm{t}=5 \mathrm{~s}$ ), where the steel layer and the insert are positioned respectively. 

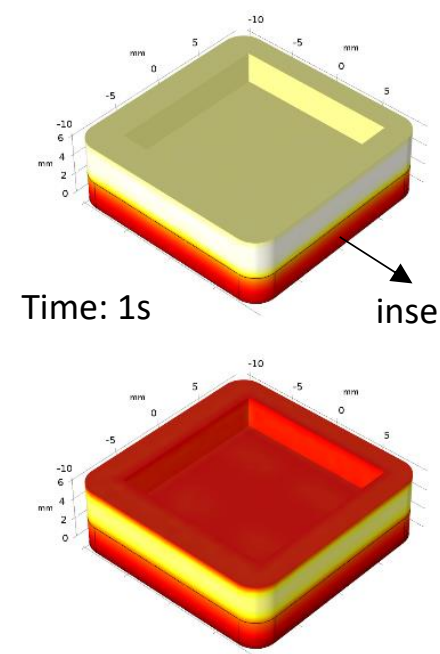

Time: $8 \mathrm{~s}$

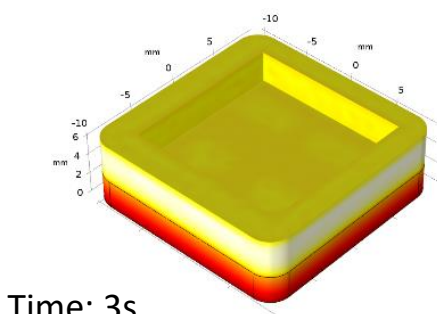

Time: $3 \mathrm{~s}$

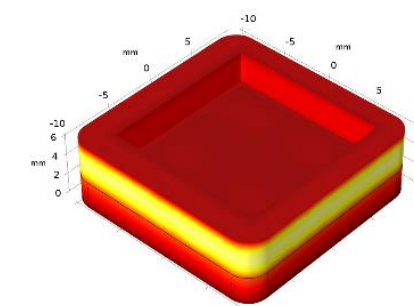

Time: 10s

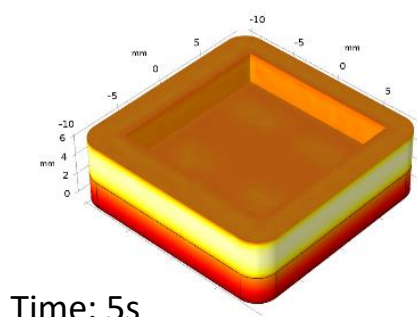

Time: $5 \mathrm{~s}$

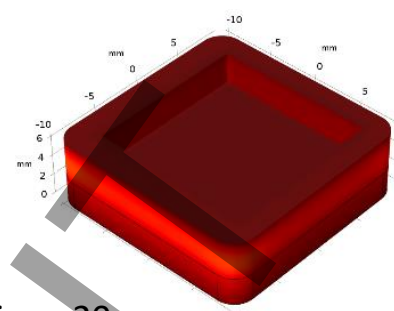

Time: 20 s

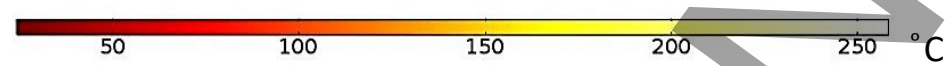

Fig 13. Temperature distribution in different times for the whole geometry.

According to Fig 13 , at $\mathrm{t}=1 \mathrm{~s}$, a relatively large temperature difference between both insert and molten material is observed, which obviously is the main driver for the heat transfer between the two. Ultimately, as also discussed earlier, both parts (insert and molten material) reach an almost equivalent final temperature of around 55 degrees Celsius, at $t=20 \mathrm{~s}$.

\subsubsection{Solidification of the melt}

To study the solidification of the molten material, the spatial variation of the melt's solid fraction ( $f s$ ) has been depicted at different timescales during the process in Fig. 14. According to Fig. 14 at $t=1 \mathrm{~s}$, most of the melt is still in liquid phase, except for the top surface where it has just come into contact with the insert. As time passes on, according to Fig. $14 \mathrm{t}=3-10 \mathrm{~s}$, the liquid material starts to release its latent heat and subsequently cools down, from both top and bottom surfaces, where according to this figure, it is in contact with insert and steel layer, respectively. At around $t=14.4 \mathrm{~s}$, the whole melt (part) is solidified.
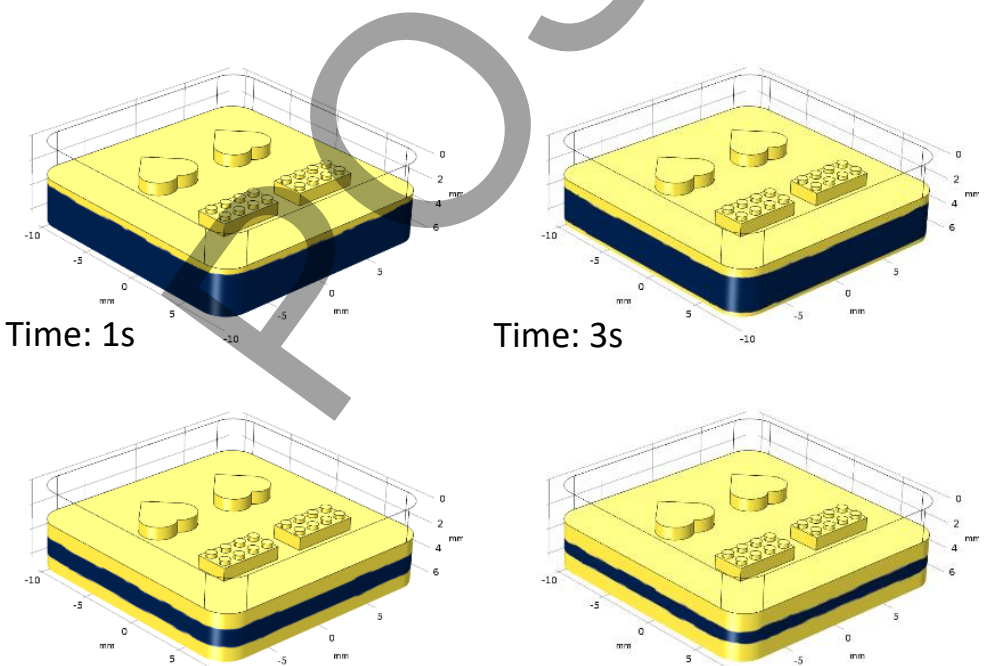

Time: $8 \mathrm{~s}$
Time: $3 \mathrm{~s}$

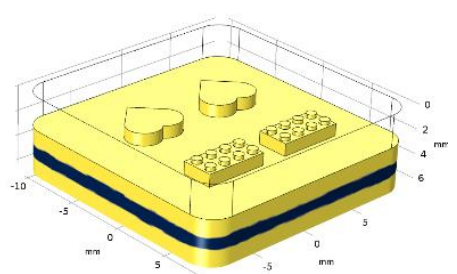

Time: 10s

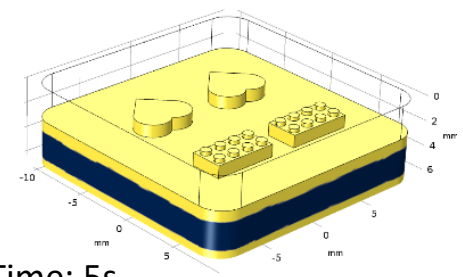

Time: $5 s$

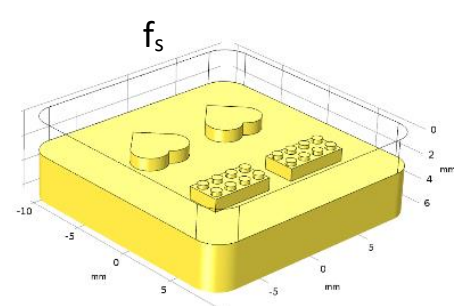

Time: $15 \mathrm{~s}$

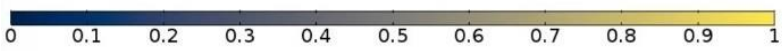

Fig 14. Molten material solid volume fraction. 
To obtain a deeper insight into the solidification pattern, the spatial variation of the solid fraction of molten material on the A-A section (Fig. 15) is shown at different times in Fig. 16:

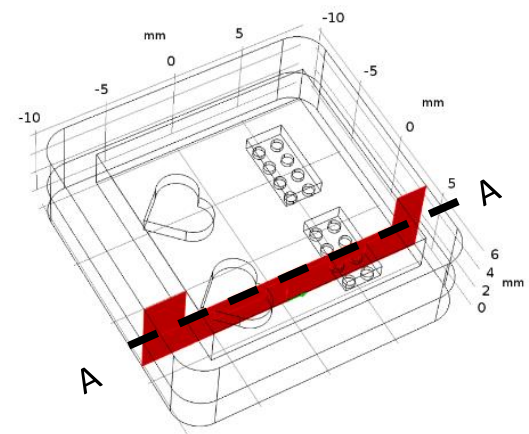

Fig 15. A view of section A-A of the molten material.

Based on Fig. 16, at $t=1 \mathrm{~s}$, a thin layer of the molten material closest to the insert will start to solidify and as time passes, at $t=3 \mathrm{~s}$ to $t=5 \mathrm{~s}$, almost all of the liquid material present in the cavities is solidified and has released its latent heat of fusion to the neighbouring insert walls. This phenomenon, as discussed earlier, contributes to the formation of hotspots on the insert surface close to these cavities, where the local temperature increases considerably. During $t=8 \mathrm{~s}$ to $\mathrm{t}=10 \mathrm{~s}$, the rest of the previously liquid material gradually becomes solid. It is also worth to mention that the sides of the molten material will solidify at a bit slower rate, compared to the inner zones. This is largely because of the fact that the sides of the melt are assumed to be adiabatic, hence the heat tends to flow towards the top, rather than to the sides. Moreover, based on Fig. 16, these zones solidify a bit later than the inner zones. However, at around $t=14.4 \mathrm{~s}$, almost all of the molten material has become solid. From this point onwards, the rest of the heat transfer occurs without phase change as just a solid state cooling.

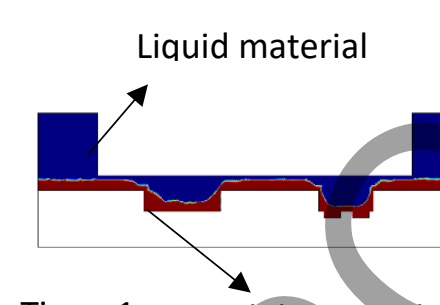

Time: 1s

Solid material
Time: 3s

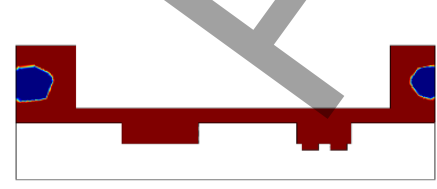

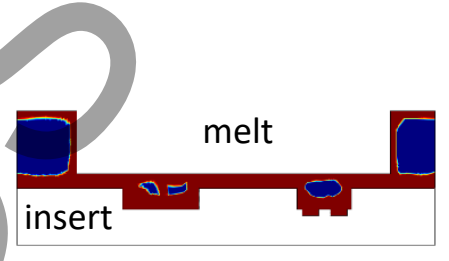

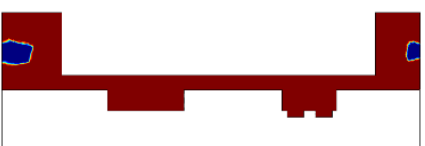

Liquid material

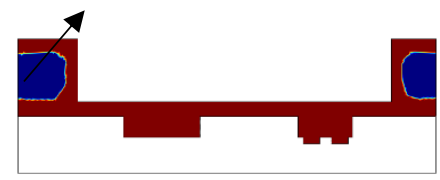

Time: $5 \mathrm{~s}$

Time: $8 \mathrm{~s}$

Time: 10 s

Time: 15s

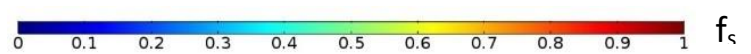

Fig 16. Solid volume fraction of molten material, section A-A. 


\subsubsection{Thermally induced stresses in the insert}

As mentioned in the modelling section, the results from the thermal analysis, i.e. the temperature field of the insert, are fed into the mechanical model via the thermal strain. To analyse the failure in the insert, both thermal stresses and yield strengths were compared at the same time and for different prescribed initial insert temperatures. Accordingly, the contours of equivalent Mises stress (see equation (18)) and yield stress are plotted in Fig. 17 at $\mathrm{t}=2$ seconds.

The highest concentration of thermal stresses occurs around the block's inner vertical edges, which are specified by the dashed line in Fig. 17 (c). Additionally, the aforementioned hotspots highly influence the insert's yield strength. Besides, the insert's yield strength has its lowest values around the horizontal edges, where the hotspots are formed, Fig. 17 (d) since for most of the materials, the yield strength monotonically decreases with temperature. Consequently the coincidence of low level of yield strengths around hotspot zones (horizontal edges) and the same time, the concentration of high level of thermally induced stresses around the inner vertical edges, causes the insert to crack where both these effects are present and dominant. The maximum value of thermally induced stresses, according to Fig. 17, would increase with increasing initial insert temperatures. Besides, their corresponding yield strength would become smaller. Hence it can be concluded that the increase of the initial insert temperature will increase the risk of failure due to the two simultaneous events described above. The numerical results demonstrate a higher stress on the corners of the features on the insert. Also the numerical model was able to precisely predict the sites of probable failure, since the simulation results completely match the failure sites observed in the experimental samples.

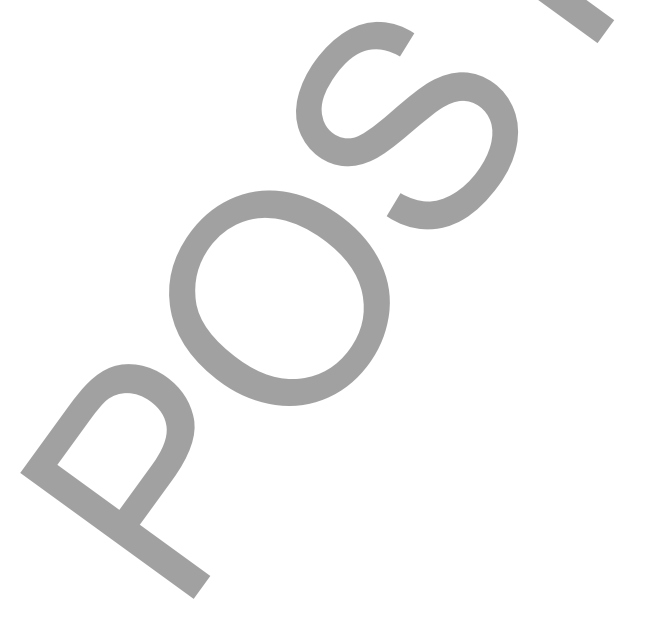




$$
\left.T\right|_{(x, y, z \in D, t=0)} ^{\text {Insert }}=25^{\circ} \mathrm{C}
$$

a)

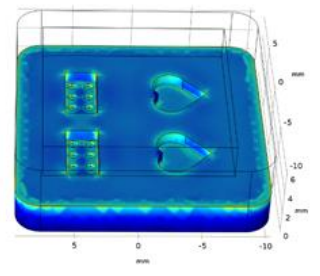

$\left.T\right|_{(x, y, z \in D, t=0)} ^{\text {Insert }}=50^{\circ} \mathrm{C}$

b)

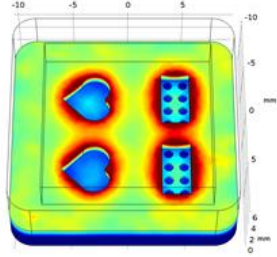

d)

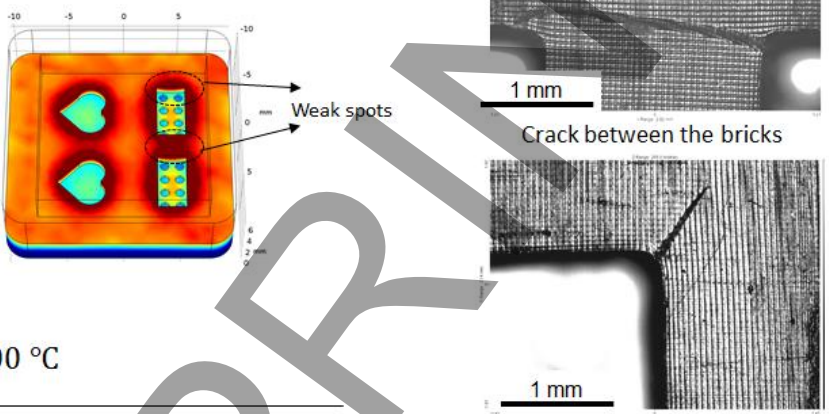

e)

$$
\left.T\right|_{(x, y, z \in D, t=0)} ^{\text {Insert }}=100^{\circ} \mathrm{C}
$$

f)

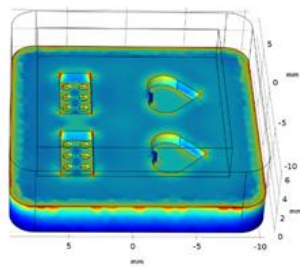

$[\mathrm{Pa}]^{2}$

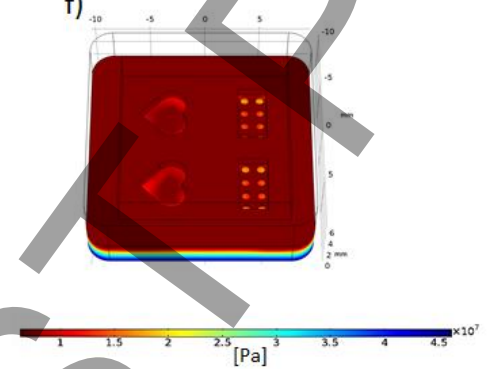

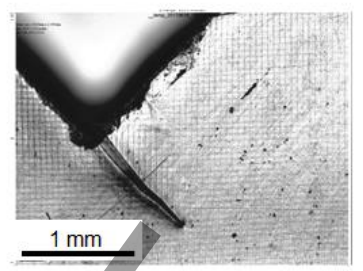

Crack below the heart $1 \mathrm{~mm}$

Crack at the top corner of brick

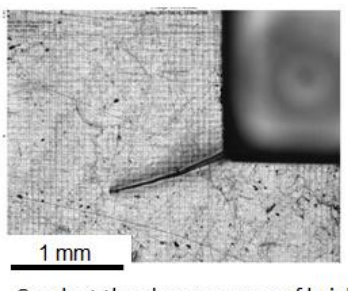

Crack at the down corner of brick

Fig 17. In the left (a), (c) and (e): Von Mises equivalent stress; (b), (d) and (f): corresponding yield strength in insert for different initial temperatures at $t=2 s$, in the right the experiments critical points

\subsubsection{Distortion of the melt (features)}

The effect of deformation of the insert on the part's (melt) shape was also considered in the modelling. The deformation of the insert can in turn distort the feature (melt), especially when the melt is still in the liquid phase, being highly deformable. The deformation of the insert at the initial phase of the melt's solidification is shown in Fig 18. The predicted deformed shape of the inserts is in good agreement with the experimental results of IM parts' wall deformation (Fig. 10). As the insert heats up (due to thermal contact with the melt), it will expand towards the hollow zones where the melt is positioned. Furthermore, at $t=2 s$ the melt is still mostly in the liquid phase according to Fig. 19 and is indeed highly deformable. Moreover, based on Fig. 19, the higher the initial mould temperature, the higher the melt's liquid state. Accordingly, since at the same time the insert is highly deformed, the melt is mostly liquid and this will cause permanent deformation and distortions in the melt (part) 
when it solidifies later on. The total deformations are shown for three prescribed initial insert temperature in Fig 18. Therefore, an increasing initial insert temperature leads to larger deformations inside the hollow parts of the insert.

At the end of the process, the final temperature of the insert will be increased to a certain level above its initial temperature. This process will be repeated after each cycle and the final insert temperature will be increased as well. Therefore it can be concluded that a higher number of cycles results in a higher final temperature and hence, the effect of a higher number of cycles can be taken into account by assuming an elevated initial temperature for the insert. In other words, a higher number of cycles will tend to heat up the insert and this effect can be simulated by considering an elevated initial temperature for the insert. It can be observed that a higher number of injection cycles or a higher initial temperature of the insert can result in higher stresses and lower tensile strength, which ultimately would contribute to higher risks of failure for the inserts.

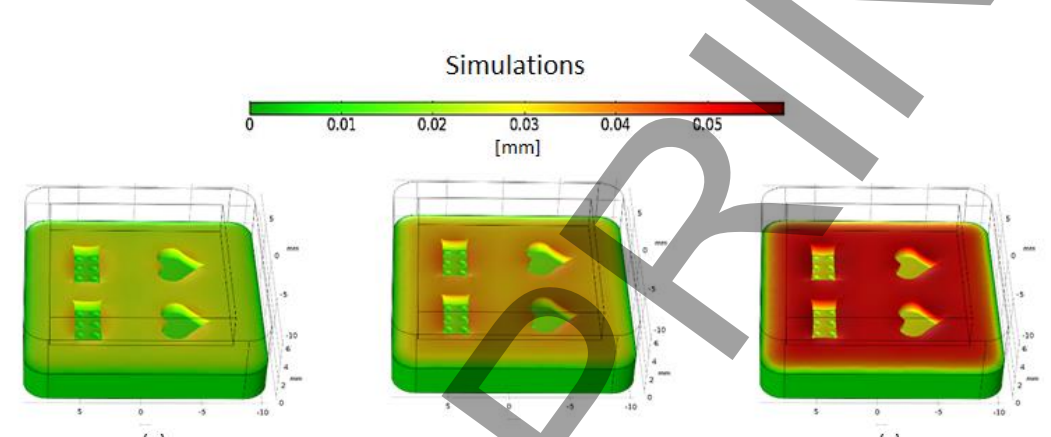

(a)

(c)

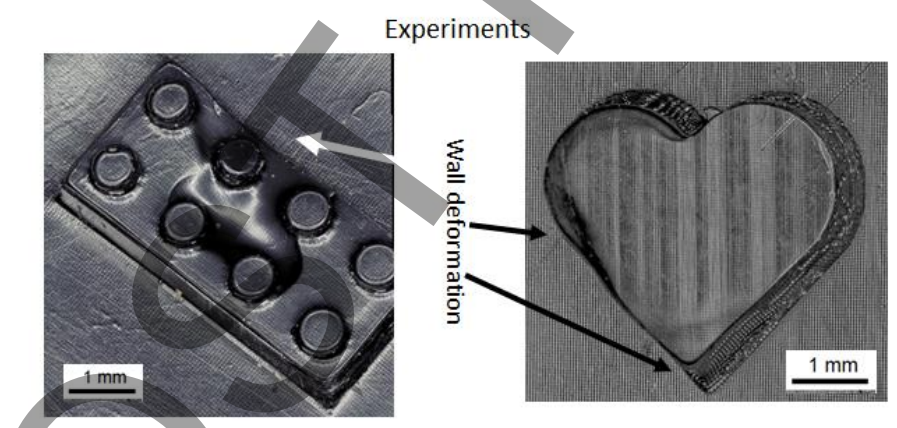

(d)

Fig 18. Insert deformation simulations for initial temperature of (a) $25^{\circ} \mathrm{C}$, (b) $50^{\circ} \mathrm{C},(\mathrm{c})$ $100^{\circ} \mathrm{C}$ at time $=2 \mathrm{~s}$ and $(\mathrm{d})$ the IM part features after insert deformation.

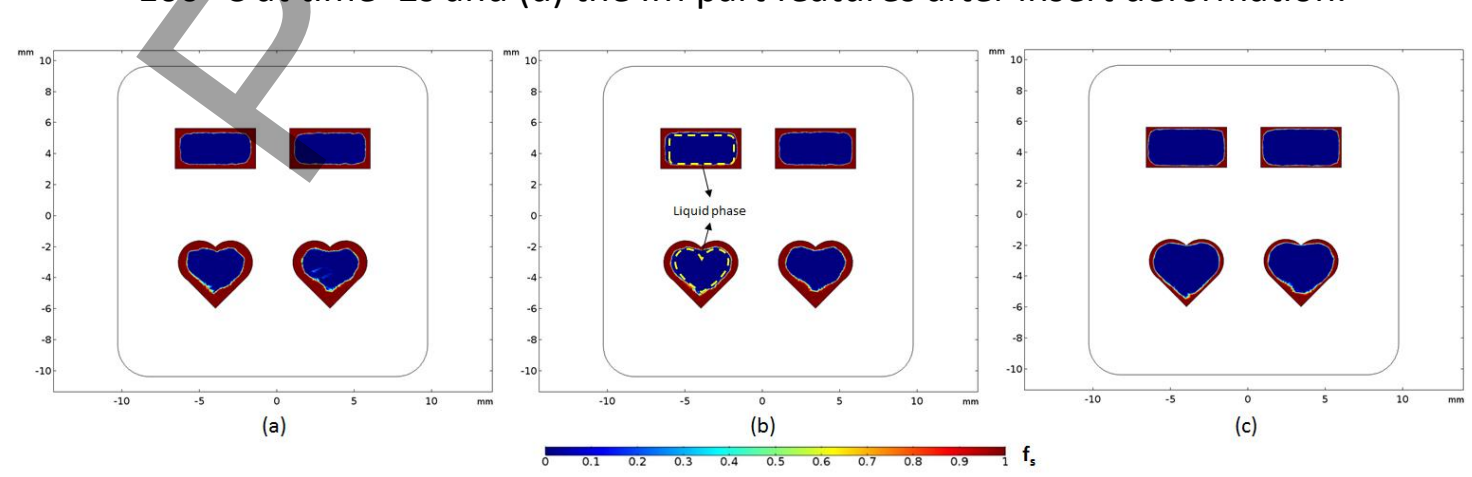

Fig 19. Solid fraction of the molten material for initial insert temperature at of (a) $25^{\circ} \mathrm{C},(\mathrm{b})$ $50^{\circ} \mathrm{C}$ and (c) $100{ }^{\circ} \mathrm{C}$ at time $=2 \mathrm{~s}$. 


\section{Conclusion}

This study aimed at investigating the soft tooling lifetime of additively manufactured inserts when integrated in an injection moulding tool and used in the IM process. The feasibility of replication of micro features of two different geometries was evaluated and the importance of the soft tooling procedure setting in IM was highlighted. The DOE technique was applied to systematically conduct the moulding experiments. A 3D thermo-mechanical finite element model of the AM insert and of the molten material was established to study the IM process. Based on the conducted work the following conclusions can be drawn.

- The preliminary setting procedure of the soft tooling was defined and the possible damages on the photopolymer insert due to misalignment of the insert, high packing pressure and different dosage of the IM material were presented. The insert failure started by the generation of cracks and was subsequently analysed. The most common place where the cracks started were determined. They were found at the corner of the features and between the features. The cracks started in the region of the insert far from the gate. Cracks mainly propagate along the injection direction.

- The DOE analysis revealed that the initial mould temperature was the most significant factor influencing the crack propagation speed. Substantially longer tool life of the inserts was observed when IM was performed at the lowest mould temperature of 25 ${ }^{\circ} \mathrm{C}$. Regarding the consistency of the features fabrication, cooling time and mould temperature were influential factors affecting the knobs' dimension. A higher replication accuracy of the knobs' dimensions was observed with the low mould temperature of $25^{\circ} \mathrm{C}$ and with higher cooling time of $5 \mathrm{~s}$.

- The simulation using the developed thermo-mechanical model was carried out for the three initial mould temperatures of $25^{\circ} \mathrm{C}, 50{ }^{\circ} \mathrm{C}$ and $100{ }^{\circ} \mathrm{C}$ with different cooling times. The solidification of the IM part and the temperature distribution in the insert were simulated. The highest concentration of thermal stresses was noticed around the block's inner vertical edges which was comparable with the cracks' location in the experimental results. By increasing the mould temperature, the yield strength was reduced and resulted in higher possibility of failure. The deformation of the insert was also simulated and the highest distortion was recorded on the wall of the features in an elevated temperature of $100^{\circ} \mathrm{C}$.

\section{Acknowledgements}

The research leading to these results has received funding from the People Programme (Marie Curie Actions) of the European Union's Seventh Framework Programme (FP7/20072013) under REA grant agreement no. 609405 (COFUNDPostdocDTU).

\section{References}

[1] S. Mellor, L. Hao, and D. Zhang, "Additive manufacturing: A framework for implementation," Int. J. Prod. Econ., vol. 149, pp. 194-201, Mar. 2014. 
[2] A. Davoudinejad, M. M. Ribo, D. B. Pedersen, A. Islam, and G. Tosello, "Direct fabrication of bio-inspired gecko-like geometries with vat polymerization additive manufacturing method," J. Micromechanics Microengineering, 2018.

[3] A. Davoudinejad, D. B. Pedersen, and G. Tosello, "Evaluation of polymer micro parts produced by additive manufacturing processes by using vat photopolymerization method," in Joint Special Interest Group meeting between euspen and ASPE Dimensional Accuracy and Surface Finish in Additive Manufacturing, 2017.

[4] A. Ovsianikov et al., "Three-dimensional laser micro-and nano-structuring of acrylated poly (ethylene glycol) materials and evaluation of their cytoxicity for tissue engineering applications," Acta Biomater., vol. 7, no. 3, pp. 967-974, 2011.

[5] C. Credi, M. Levi, S. Turri, and G. Simeone, "Stereolithography of perfluoropolyethers for the microfabrication of robust omniphobic surfaces," Appl. Surf. Sci., vol. 404, pp. 268-275, May 2017.

[6] A. D. Lantada, V. Piotter, K. Plewa, N. Barié, M. Guttmann, and M. Wissmann, "Toward mass production of microtextured microdevices: linking rapid prototyping with microinjection molding," Int. J. Adv. Manuf. Technol., vol. 76, no. 5-8, pp. 10111020, 2014.

[7] Y. Zhang, D. B. Pedersen, A. S. Gøtje, M. Mischkot, and G. Tosello, "A Soft Tooling process chain employing Additive Manufacturing forinjection molding of a 3D component with micro pillars," J. Manuf. Process., vol. 27, pp. 138-144.

[8] M. Mischkot, A. Davoudinejad, A. Charalambis, G. Tosello, D. B. Pedersen, and H. Nørgaard, "Dimensional accuracy of Acrylonitrile Butadiene Styrene injection molded parts produced in a pilot production with an additively manufactured insert," in 33rd Conference of the Polymer Processing Society, at Cancun, Mexico, 2017.

[9] J. G. Kovacs, G. Kortelyesi, N. K. Kovacs, and A. Suplicz, "Evaluation of measured and calculated thermal parameters of a photopolymer," Int. Commun. Heat Mass Transf., vol. 38, no. 7, pp. 863-867, 2011.

[10] W. Cao, L. Kong, Q. Li, J. Ying, and C. Shen, "Model and simulation for melt flow in micro-injection molding based on the PTT model," Model. Simul. Mater. Sci. Eng., vol. 19 , no. 8 , p. $85003,2011$.

[11] C. A. Griffiths, S. S. Dimov, E. B. Brousseau, and M. S. Packianather, "The finite element analysis of melt flow behaviour in micro-injection moulding," Proc. Inst. Mech. Eng. Part B J. Eng. Manuf., vol. 222, no. 9, pp. 1107-1118, 2008.

[12] P. Guerrier, G. Tosello, K. K. Nielsen, and J. H. Hattel, "Three-dimensional numerical modeling of an induction heated injection molding tool with flow visualization," Int. J. Adv. Manuf. Technol., vol. 85, no. 1, pp. 643-660, Jul. 2016.

[13] M. La, J. G. Lee, and S. J. Park, "Numerical and experimental investigation of plastic injection molding of micro-engineered surfaces," Polym. Eng. Sci., Jun. 2017.

[14] K. Metwally, T. Barriere, and C. Khan-Malek, "Replication of micrometric and submicrometric structured surfaces using micro-injection and micro-injection compression moulding," Int. J. Adv. Manuf. Technol., vol. 83, no. 5, pp. 779-789, Mar. 
2016.

[15] S.-J. Choi and S. K. Kim, "Multi-scale filling simulation of micro-injection molding process," J. Mech. Sci. Technol., vol. 25, no. 1, pp. 117-124, Jan. 2011.

[16] C. Rytka, J. Lungershausen, P. M. Kristiansen, and A. Neyer, "3D filling simulation of micro-and nanostructures in comparison to iso-and variothermal injection moulding trials," J. Micromechanics Microengineering, vol. 26, no. 6, p. 65018, 2016.

[17] T. A. butadiene styrene DataSheet, "Terluran GP-35 Terluran GP-35," 2016. .

[18] C. A. Griffiths, S. S. Dimov, E. B. Brousseau, and R. T. Hoyle, "The effects of tool surface quality in micro-injection moulding," J. Mater. Process. Technol., vol. 189, no. 1-3, pp. 418-427, Jul. 2007.

[19] P. Guerrier, G. Tosello, and J. H. Hattel, "Flow visualization and simulation of the filling process during injection molding," CIRP J. Manuf. Sci. Technol., vol. 16, pp. 1220, Jan. 2017.

[20] B. Ozcelik, A. Ozbay, and E. Demirbas, "Influence of injection parameters and mold materials on mechanical properties of ABS in plastic injection molding," Int. Commun. Heat Mass Transf., vol. 37, no. 9, pp. 1359-1365, Nov. 2010.

[21] D. P. D. THEODORE L. BERGMAN, ADRIENNE S. LAVINE, FRANK P. INCROPERA, Fundamentals of Heat and Mass Transfer. John Wiley \& Sons, 2002.

[22] M. Hafid and M. Lacroix, "Inverse heat transfer prediction of the state of the brick wall of a melting furnace," Appl. Therm. Eng., vol. 110, pp. 265-274, Jan. 2017.

[23] N. Pryds, J. Thorborg, M. Lipinski, and M. Schneider, Fundamentals of numerical modelling of casting processes. Polyteknisk Forlag, 2005.

[24] J. P. Holman, "Heat transfer, 9th." McGraw-Hill, 2002.

[25] T. A. Osswald and J. P. Hernández-Ortiz, "Polymer Processing," in Polymer Processing, T. A. Osswald and J. P. Hernández-Ortiz, Eds. Hanser, 2006, pp. i-xxvii.

[26] A. P. Boresi, R.J. Schmidt, and O. M. Sidebottom, Advanced mechanics of materials, vol. 6. Wiley New York, 1993.

[27] M. H. Sadd, Elasticity: theory, applications, and numerics. Academic Press, 2009.

[28] R. G. Budynas, J. K. Nisbett, and others, Shigley's mechanical engineering design, vol. 8. McGraw-Hill New York, 2008.

[29] W.-F. Chen and D.-J. Han, Plasticity for structural engineers. J. Ross publishing, 2007. 